\title{
Trafficking Mechanisms of Synaptogenic Cell Adhesion Molecules
}

Luís F. Ribeiro1, 2, Ben Verpoort1, 2 and Joris de Wit $1,2,{ }^{*}$

\section{Affiliations:}

${ }_{1}$ VIB Center for Brain \& Disease Research, Herestraat 49, 3000 Leuven, Belgium ${ }_{2}$ KU Leuven, Department of Neurosciences, Herestraat 49, 3000 Leuven, Belgium

* Correspondence: joris.dewit@kuleuven.vib.be; phone: +32-16373254 


\begin{abstract}
Nearly every aspect of neuronal function, from wiring to information processing, critically depends on the highly polarized architecture of neurons. Establishing and maintaining the distinct molecular composition of axonal and dendritic compartments requires precise control over the trafficking of the proteins that make up these cellular domains. Synaptic cell adhesion molecules (CAMs), membrane proteins with a critical role in the formation, differentiation and plasticity of synapses, require targeting to the correct pre- or postsynaptic compartment for proper functioning of neural circuits. However, the mechanisms that control the polarized trafficking, synaptic targeting, and synaptic abundance of CAMs are poorly understood. Here, we summarize current knowledge about the sequential trafficking events along the secretory pathway that control the polarized surface distribution of synaptic CAMs, and discuss how their synaptic targeting and abundance is additionally influenced by post-secretory determinants. The identification of trafficking-impairing mutations in CAMs associated with various neurodevelopmental disorders underscores the importance of correct protein trafficking for normal brain function.
\end{abstract}

\title{
Keywords
}

Neuronal polarity / Synaptogenesis / Cell adhesion molecules / Secretory pathway /

Endosome-associated sorting stations / Neurodevelopmental disorders 


\section{Introduction}

Neurons are highly polarized cells composed of two major structurally and functionally distinct cellular domains, which differ in their molecular composition: the somatodendritic domain that receives and integrates synaptic input, and the axonal domain that propagates and transmits the electrical signal to downstream neurons or other target cells (Craig and Banker, 1994). Together, these domains are organized into transcellular units at highly specialized cellular junctions, known as synapses, which enable efficient information processing between neurons (Biederer et al., 2017). Both domains are composed of large and distinct protein complexes, which are built from the neuron's repertoire of scaffolding proteins, neurotransmitter receptors, ion channels and cell adhesion molecules (CAMs) (Emes and Grant, 2012). Importantly, virtually every aspect of neuronal development, signalling, and plasticity critically depends on the appropriate localization and polarized distribution of these protein complexes (Terenzio et al., 2017). As neurons are among the morphologically most complex cells, faithful delivery of their membrane constituents to the correct cellular compartment to maintain its molecular and functional integrity is a challenging task.

Receptors mediating cell adhesion are fundamental components of the synaptic surface proteome. In recent decades, a multitude of trans-synaptic adhesive interactions that regulate various aspects of synaptic development has been identified. Neurexins (NRXNs) and LAR-type receptor protein tyrosine phosphatases (RPTPS) act as presynaptic adhesive platforms that engage in trans-synaptic complex formation with a wide variety of structurally diverse postsynaptic CAMs, including neuroligins (NLGNs) (Südhof, 2017; Takahashi and Craig, 2013). In addition, many more adhesive complexes bridging the synaptic cleft with a role in synapse development were identified, such as cadherins, leucine-rich repeat (LRR) proteins, and members of the immunoglobulin (lg)-domain containing superfamily (Giagtzoglou et al., 2009). Synaptic CAMs not only mediate cell-cell recognition and the initial establishment of synaptic contacts through their extracellular adhesive domains, but also contribute to the functional specification of synapses via their ability to recruit components of the pre- and postsynaptic signalling machinery (Jang et al., 2017; Siddiqui and Craig, 2011). Furthermore, the existence of cell type-specific repertoires of CAMs and their role as major synaptic organizers strongly support the notion that these surface proteins contribute to the specific wiring of neural circuits (de Wit and Ghosh, 2016). Consequently, mutations and copy number variations in genes encoding synaptic CAMs were found to be associated with several neurodevelopmental disorders such as autism and schizophrenia, highlighting the functional importance of synaptic CAMs for normal brain function (Chen et al., 2014; de Wit and Ghosh, 2014; Lin et al., 2016; Südhof, 2008). Despite the essential roles of CAMs in the establishment, differentiation and specification of synaptic contacts, surprisingly little is known about the trafficking itinerary that governs their synaptic targeting. In view of the major role that these 
fundamental synaptic building blocks play in brain function, a better understanding of how CAMs reach their site of action, and how their polarized distribution and abundance at synapses is controlled, is needed.

In this review, we first provide an overview of the trafficking stages along the secretory pathway that regulate the surface and synaptic targeting of CAMs. We then highlight the emergence of key sorting stations within the endosomal compartment and discuss how they are involved in the maintenance of synaptic protein homeostasis. Lastly, we emphasize the importance of correct protein trafficking for normal brain function, as exemplified by the identification of several trafficking-impairing mutations in CAMs associated with various neurodevelopmental disorders. We limit our discussion to synaptogenic CAMs (Figure 1), defined here as having the ability to induce pre- or postsynaptic differentiation when presented on the surface of non-neuronal cells (Biederer and Scheiffele, 2007). As a consequence of limited available literature, this review mainly centers around NRXN- and NLGN-related trafficking events. For an overview on the nanoscale organization and dynamic turnover of CAMs at the synapse, we refer the reader to an excellent review (Chamma and Thoumine) in this issue of Molecular and Cellular Neuroscience.

\section{Trafficking along the secretory pathway}

Given their complex morphology, neurons have developed intricate mechanisms to ensure accurate delivery of membrane proteins to the appropriate cellular compartment (Bentley and Banker, 2016). A series of highly organized compartments that include the endoplasmic reticulum (ER), the ER-to-Golgi intermediate compartment (ERGIC), and the trans-Golgi network (TGN) constitute the core biosynthetic machinery (Horton and Ehlers, 2004). Transport vesicles emanating from the TGN are actively trafficked towards their final destination via cytoskeletal-based transport and subsequently delivered to the plasma membrane by exocytosis, which involves soluble $\mathrm{N}$-ethylmaleimide-sensitive factor attachment protein receptors (SNAREs) catalyzing membrane fusion. In this section, we summarize how these sequential and finely-tuned trafficking events regulate the surface and synaptic expression of synaptogenic CAMs (Figure 2).

\section{ER exit control}

The ER has been implicated in the quality control of proteins entering the secretory pathway (Ellgaard and Helenius, 2003). Various sequences present in the ectodomain, transmembrane region, or cytosolic domain of CAMs have been implicated in the exit from the ER, exerting their effect via proteolytic cleavage, dimerization or PDZ-binding. 


\section{Proteolytic cleavage}

Proteolytic cleavage has been shown to be involved in protein maturation and trafficking at the ER (Braakman and Hebert, 2013). Recently, Xie and colleagues demonstrated that cleavage of Drosophila NLGN2 (dNLGN2) at the ER is required for its surface and synaptic expression (Tu et al., 2017). The $130 \mathrm{kDa}$ uncleaved form of dNLGN2 is highly enriched in the ER. Here, dNLGN2 is cleaved at a region that encompasses Y642-T698, which is located in its extracellular cholinesterase (ChE)-like domain, and subsequently delivered to the Golgiapparatus as a membrane-tethered C-terminal fragment (CTF) of $70 \mathrm{kDa}$, the most abundant form of NLGN2 in Drosophila (Tu et al., 2017). Consistently, only the $70 \mathrm{kDa}$ form could be detected in plasma membrane fractions purified from fly heads (Tu et al., 2017). The $70 \mathrm{kDa}$ form consists of a small portion of the extracellular domain that lacks the ChE-like domain, followed by the transmembrane and cytosolic domains. In order to dissect the mechanism of dNLGN2 proteolytic processing in vivo, Xie and colleagues generated transgenic flies overexpressing WT dNLGN2, cleavage-defective (dNLGN2sF) or cleavage-mimicking (dNLGN2ctF) mutants. The ER-resident chaperone BiP was shown to interact in vivo with WT dNLGN2 and dNLGN2sF, but not with dNLGN2CTF, indicating that only the full-length (FL) protein is retained in the ER (Tu et al., 2017). In addition, loss of BiP in flies overexpressing WT dNLGN2 leads to increased levels of the uncleaved form, as opposed to a decrease in the cleaved form (Tu et al., 2017). Overall, these observations indicate that BiP is involved in the proteolytic cleavage of dNLGN2 at Y642-T698 (Table 1). Moreover, dNLGN2sF was unable to be delivered to dendritic sites, whereas WT dNLGN2 and dNLGN2ctF were properly translocated to dendrites and could rescue the synaptic defects at the neuromuscular junction (NMJ) observed in dNLGN2 null mutant flies (Tu et al., 2017). This last set of results suggests that the $70 \mathrm{kDa}$ form (lacking the ChE-like domain that mediates binding to NRXNs) regulates NMJ development in a NRXN-independent mechanism. This observation is consistent with previous data showing that the cytoplasmic domain of NLGN1, rather than NRXN-binding, is necessary and sufficient for the induction of dendritic spines in cultured neurons (Ko et al., 2009b; Shipman et al., 2011). Furthermore, overexpression of NLGN1-CTF has been shown to retain the capacity to induce dendritic spines in hippocampal granule cells (Suzuki et al., 2012). Whether proteolytic processing of NLGNs in mammals is also required for ER exit is currently unknown.

\section{Dimerization}

In addition to proteolytic cleavage, dimerization has also been shown to be involved in trafficking at the ER. It has been proposed that oligomerization has to occur before ER exit to make sure that only fully oligomerized functional protein complexes arrive at their appropriate membrane destination. For instance, this phenomenon has been demonstrated to be required 
for GABAA receptor trafficking (Jacob et al., 2008). NLGN trafficking may depend on the same mechanism (Poulopoulos et al., 2012), although conflicting results have been reported (Ko et al., 2009b; Shipman and Nicoll, 2012). Expression of a NLGN2 mutant (mono-NLGN2) that does not dimerize (E603A/L604A mutation of the ectodomain) in cultured neurons led to accumulation of NLGN2 in the soma and subsequent cell death (Poulopoulos et al., 2012). This observation indicates that NLGN2 dimerization is required for its surface expression in neurons. Expression of mono-NLGN2 in heterologous cells, which are tolerant to the expression of mono-NLGN2, increased the levels of immature NLGN2 (carrying ER-associated $\mathrm{N}$-linked glycans) that is confined to intracellular secretory compartments (Poulopoulos et al., 2012). These results suggest that NLGN2 monomers are retained in the secretory pathway and that dimerization is required for efficient NLGN2 surface expression. The trafficking impairments of mono-NLGN2 were rescued when a single residue residing in the monoNLGN2 transmembrane region (N691) was mutated from an asparagine to a hydrophobic leucine (Poulopoulos et al., 2012), indicating that the monomers were now able to traverse the secretory pathway (Table 1). The authors hypothesized that nascent immature monomeric NLGN2 is retained in the ER via an interaction between its exposed transmembrane asparagine residue and an ER-resident protein. Consistent with this hypothesis, the transmembrane domains of all NLGNs are highly conserved, each containing an asparagine residue within their hydrophobic stretch. Nevertheless, further work needs to be performed to identify such protein(s) and to evaluate whether NLGN dimerization would interfere with this binding.

Südhof and colleagues identified additional mutations in the ectodomain (F458A/W463A and F458A/M459A/W463A) that abolish NLGN1 dimerization (Ko et al., 2009b). When these mutants were expressed in heterologous cells, surface expression was comparable to wild-type (WT) NLGN1 (Ko et al., 2009b). This observation has been reproduced by an independent laboratory in cultured neurons (Shipman and Nicoll, 2012). Expression of NLGN1 or NLGN3 dimerization-defective mutants of the ectodomain (NLGN1: E628A/L629A, K622A/V623A, F458A/M459A/W463A; NLGN3: H606A/L607A, K600A/V601A, F437A/M438A/W442A described by Dean et al., 2003; Ko et al., 2009b) led to comparable surface levels as their WT counterparts (Shipman and Nicoll, 2012). These observations suggest that monomeric NLGN1 and NLGN3 are able to reach the cellular surface. Different levels of overexpression, or possible misfolding of mutant proteins, might account for some of the discrepancies observed between these studies. A systematic analysis of the effect of these mutations on trafficking of different NLGN family members in the same model system could resolve these issues. 


\section{PDZ-binding}

In case of the presynaptic NLGN-binding partner NRXN, the cytoplasmic PDZ-binding motif has been shown to facilitate its transition from the ER to the cell surface, although contradictory results have been reported. Deletion of the PDZ-binding motif abolished surface expression of NRXN1 $\alpha$ and resulted in an intense peri-nuclear distribution, presumably the ER (Fairless et al., 2008) (Table 1). Corroborating these findings, deletion of the PDZ-binding motif of NRXN3 $\beta$ or replacing its sequence with alanines caused a decrease in the surface levels of NRXN3 $\beta$ (Gokce and Südhof, 2013) (Table 1). The PDZ-binding motif could drive NRXN ER exit either via direct binding to a PDZ domain-containing interaction partner or by suppressing an ER retention motif (as described for NMDA receptor trafficking; Standley et al., 2000). To dissect the mechanism of NRXN1 $\alpha$ ER exit, putative ER retention sites were mutated either alone or in combination with PDZ-binding motif mutations. Despite the effort, no ER retention site was found (Fairless et al., 2008). In addition, other reports have shown that expression in cultured neurons and in heterologous cells of a deletion mutant lacking the cytoplasmic domain does not affect surface localization of NRXN1 $\beta$ (Dean et al., 2003; Rabaneda et al., 2014), suggesting that the PDZ-binding motif may only be required for ER exit in the presence of the other motifs in the NRXN cytoplasmic domain. The deletion of the PDZ-binding motif might unmask non-canonical putative ER/Golgi-complex retention sites, located upstream in the cytoplasmic domain, that are inactive when the PDZ-binding motif is present. Possibly, deletion mutants of NRXN lacking the cytoplasmic domain (Dean et al., 2003; Rabaneda et al., 2014) take a different, PDZ-binding motif-independent, trafficking pathway.

\section{Sorting at the TGN}

Newly synthesized membrane proteins are packaged into distinct transport carriers within the TGN that are then sorted to different cellular compartments. One of the major mechanisms that cells use to sort transport carriers involves the recognition of specific motifs, generally present in the cytosolic domains of the cargo proteins, by heterotetrameric adaptor proteins (AP) localized at the TGN (Bonifacino, 2014; Guo et al., 2014). In neurons, AP-1 has been implicated in the sorting of membrane proteins to the somatodendritic compartment (Dwyer et al., 2001; Farías et al., 2012; Jain et al., 2015; Margeta et al., 2009; Zhou et al., 2016). AP-3 seems to be required to localize axonal proteins to synaptic vesicles (SV) (Nakatsu et al., 2004; Newell-Litwa et al., 2009; Salazar, 2003; Salazar et al., 2004). Consistent with this idea, Shen and colleagues showed that neuronal membrane proteins are sorted by a simple mechanism. They proposed that AP-3 and AP-1 reside in adjacent domains at the Golgi-apparatus, where they sort membrane proteins into distinct pools of vesicles that are selectively targeted to the axon or dendrites, respectively (Li et al., 2016). According to their model, dendritic or axonal dileucine ([D/E]xxxL[L/l])- and tyrosine (YxxФ)-based sorting motifs possess distinct binding 
efficiencies for AP-3 and AP-1 (Li et al., 2016). More specifically, it was shown that AP-3 binds strongly to axonal sorting motifs, but weakly to dendritic sorting motifs ( $\mathrm{Li}$ et al., 2016). In contrast, AP-1 bound with similar efficiencies to dendritic and axonal sorting motifs (Li et al., 2016). These findings indicate that AP-3 selects axonal cargos by firm binding to axonal dileucine or tyrosine based motifs. This study was performed in a specific type of unipolar neurons in C. elegans, the RIA neurons, which contain a single neurite compartmentalized into a proximal dendritic segment and a distal axonal segment (White et al., 1986). Whether this model is generally applicable to other types of neurons or to other organisms awaits confirmation. Interestingly, dileucine or tyrosine based motifs were found in many polarized membrane proteins from mouse neurons, including some synaptogenic CAMs from the LRR and ephrin receptor families (Li et al., 2016). This finding supports the idea that AP-mediated sorting might represent a general mechanism to target neuronal membrane proteins to the right cellular compartment.

\section{Microtubule-mediated transport}

TGN-derived vesicles are actively trafficked along cytoskeletal filaments to their appropriate destination by molecular motors (Hirokawa et al., 2009). It has been shown that NRXN is cotransported in synaptic vesicle protein transport vesicles (STVs) via fast microtubule-mediated transport (Neupert et al., 2015). On the other hand, the identity of NLGN-positive vesicles, and their cargo adaptors and motor proteins that control NLGN anterograde transport is currently unknown.

NRXN1-positive vesicles were found both in axons (unidirectional anterograde movement) and dendrites (bidirectional movement) (Neupert et al., 2015). Moreover, NRXN1 $\alpha$ migrated slower than NRXN1 $\beta$, and NRXN1 in the axon moved faster than in dendrites (Neupert et al., 2015). Additionally, it was found that NRXN1-positive vesicles colocalized with markers of STVs, such as synaptophysin, synapsin and synaptotagmin-1 (Neupert et al., 2015) and with proteins that were shown to bind the NRXN cytoplasmic domain, such as CASK or Mint (Fairless et al., 2008; Neupert et al., 2015). This observation was confirmed by live cellimaging, in which co-expression of NRXN1a or NRXN1 $\beta$ with synaptophysin showed synchronous movement of clusters positive for NRXN1 and synaptophysin in both processes (Neupert et al., 2015). Moreover, spontaneous appearance of surface NRXN fluorescence was always accompanied by an increase of synaptophysin fluorescence (Neupert et al., 2015), further supporting the idea that NRXN1 is transported as cargo on STVs. Although these observations suggest NRXN transport along STVs, this should be interpreted with some caution, because these experiments were performed by expressing NRXN exogenously and by using confocal microscopy, which lacks sufficient resolution for the detection of co-transport in the same vesicle. Heine and colleagues further tested if the intracellular transport of NRXN1 
requires the cytoskeleton motor protein KIF1A, such as proposed for STVs (Hirokawa et al., 2009). Nocodazole treatment (to inhibit microtubule polymerization), but not treatment with latrunculin (which blocks F-actin formation), dramatically reduced the movement of NRXN1positive vesicles in axons and dendrites (Neupert et al., 2015). Coclusters containing NRXN1/KIF1A moved with the same velocity as NRXN1/synaptophysin-containing coclusters (Neupert et al., 2015). Knockdown (KD) of KIF1A led to an accumulation of NRXN1-positive vesicles in the soma and in the initial segment of the axon (Neupert et al., 2015). Together, these observations suggest that NRXN1 is co-transported with STVs via fast microtubulemediated transport.

Although not studied as extensively as the prototypical NRXN-NLGN complex, dendritic targeting of the ephrin type-B receptor 2 (EphB2) has been proposed to involve an interplay between the PDZ-domain containing scaffold glutamate receptor interacting protein 1 (GRIP1) and the microtubule motor protein kinesin-1 (also known as KIF5) (Hoogenraad et al., 2005). ShRNA-mediated KD of GRIP1 in cultured neurons resulted in a marked decrease of EphB2 surface levels in dendrites. Importantly, loss of GRIP1 also changed the intracellular distribution of EphB2, leading to an accumulation in the Golgi compartment. Furthermore, EphB2 lacking its PDZ-binding domain that is responsible for binding to GRIP1 (Torres et al., 1998), similarly accumulated in the Golgi compartment and did not colocalize with endogenous GRIP1 in dendrites (Hoogenraad et al., 2005). This finding reinforces the hypothesis that GRIP1 is required for post-Golgi trafficking of EphB2 to dendrites. In line with the observation that GRIP1 binds to KIF5 (Setou et al., 2002), KIF5 also mislocalized to the Golgi compartment in GRIP1 KD neurons. To interfere with the specific interaction of GRIP1 and KIF5, two dominant-negative constructs were engineered to abolish their reciprocal binding, each causing a drastic reduction in the dendritic surface levels and a mislocalization of EphB2 when expressed in cultured neurons (Hoogenraad et al., 2005). These findings indicate that the GRIP1-KIF5 interaction is crucial for the proper targeting of EphB2 to the dendritic surface. Emerging evidence demonstrates that synaptic scaffolds such as GRIP1 and other related membrane-associated guanylate kinases (MAGUKs) perform more elaborate functions that extend beyond the anchoring and clustering of synaptic membrane proteins (Box 1). Instead, these multi-PDZ domain containing proteins act as linker molecules between motor proteins and various neurotransmitters receptors or synaptogenic proteins, including CAMs, to ensure correct cargo transport towards their appropriate destination (Heisler et al., 2014; Hoogenraad et al., 2005; Jeyifous et al., 2009; Schapitz et al., 2010; Setou et al., 2000, 2002; Terauchi et al., 2015). 


\section{SNARE-mediated surface insertion}

After reaching the correct subcellular compartment, vesicles packed with membrane proteins have to be inserted at a specific region of the plasma membrane. SNARE proteins are the main components of the molecular machinery that trigger intracellular membrane fusion at the target membrane (Jahn and Scheller, 2006; Martens and McMahon, 2008; Rizo and Südhof, 2012; Südhof and Rothman, 2009). The SNARE-fusion complexes include members of the syntaxin (Stx), SNAP-23/25, and synaptobrevin/VAMP protein families (Jahn and Scheller, 2006; Martens and McMahon, 2008; Rizo and Südhof, 2012; Südhof and Rothman, 2009). Importantly, the presence of specific SNARE complexes on the donor compartment and on the acceptor compartment ensures the specificity of vesicle fusion at the appropriate membrane location. One classical example consists of vesicular R-SNARE proteins synaptobrevin/VAMP interacting with two target Q-SNARE proteins SNAP-25 and Stx1, that operate with SNAREassociated proteins, to trigger neurotransmitter release at presynaptic nerve terminals (Jahn et al., 2003; Rizo and Rosenmund, 2008; Südhof, 2004; Südhof and Rothman, 2009).

In polarized epithelial cells, the differential subcellular localization of Stx4 (basolateral) and Stx3 (apical) controls the selective fusion of carriers with the basolateral and apical membranes, respectively (Low et al., 1996, 1998, 2002; Reales et al., 2011; Sharma et al., 2006; ter Beest et al., 2005). In fact, much of the current knowledge on the molecular mechanisms controlling the targeting of membrane proteins in neurons still comes from possible analogies with polarized epithelial cells (Bentley and Banker, 2016; Craig and Banker, 1994), where the basolateral and apical domains are thought to be the equivalent of the somatodendritic and axonal compartments, respectively, in neurons.

Despite conflicting results regarding the subcellular distribution of Stx4 and Stx3 in neurons (Harris et al., 2016; Jurado et al., 2013; Kennedy et al., 2010; Soo Hoo et al., 2016), they have recently been linked to the proper surface targeting of NLGN1 and NRXN1 (Harris et al., 2016; Soo Hoo et al., 2016), respectively. Littleton and colleagues found that postsynaptic levels of NLGN1 were decreased at the NMJ in Stx4 null mutant flies (Harris et al., 2016). Decreased NLGN1 levels at the plasma membrane after loss of Stx4 seemed to be caused either by changes in the surface delivery or in the surface removal of NLGN1, since its surface mobility was unaltered. Interestingly, the mistargeting phenotype of NLGN1 caused by loss of Stx4 was exacerbated upon deletion of the NLGN1 cytoplasmic domain (Harris et al., 2016). Therefore, the authors hypothesized that NLGN1 surface localization is likely to involve two steps: i) Stx4-dependent membrane insertion and ii) membrane stabilization that depends on protein interaction with its cytoplasmic domain (which includes a PDZ-binding motif).

In contrast to NLGN1, NRXN1 trafficking was shown to be dependent on Stx3. To address whether Stx 3 contributes to NRXN axonal polarization, Vandenberg and colleagues generated Stx3 mutants that mislocalize to dendrites (Soo Hoo et al., 2016). Despite conflicting 
results (Jurado et al., 2013), Stx3 has been shown to be localized specifically to the axon (Soo Hoo et al., 2016), like in epithelial cells. Co-expression of NRXN1 $\alpha$ and Stx3 mutants in cultured neurons disrupted the axonal polarization of NRXN1 $\alpha$ (Soo Hoo et al., 2016). However, the polarized distribution of a dendritic cargo protein, transferrin receptor (TfR), was not affected upon co-expression of the Stx3 mutants, indicating that Stx3 is involved in polarization of axonal cargos (Soo Hoo et al., 2016). Overall these observations suggest that Stx3 and Stx4 participate in the polarized targeting of membrane proteins in neurons, such as synaptogenic CAMs.

\section{Synaptic targeting and abundance}

Different trafficking events operate in concert to control the surface levels of synaptogenic CAMs. Following exocytosis, either at synaptic sites or at extrasynaptic sites, lateral diffusion, endocytic recycling and cleavage take place in order to fulfil the demand for synaptic receptors throughout synaptic development or upon changes in activity (Figure 2). Moreover, the presence of certain cis-motifs in their cytoplasmic domains controls their surface and synaptic clustering, thereby controlling their dendritic/axonal polarization (Table 1). Finally, additional aspects, such as alternative splicing (Chih et al., 2006; Fu and Huang, 2010; Neupert et al., 2015), trans-synaptic interactions (Dean et al., 2003; Fu and Huang, 2010; Futai et al., 2013; Kang et al., 2008; Saura et al., 2011) and protein-protein interactions of CAMs with scaffold proteins also dictate their synaptic balance and specific synaptic distribution (Box 1).

\section{Cis-motifs control polarization of CAMs}

While sorting motifs that regulate the differential distribution between the somatodendritic and axonal domain have been described for NLGN and LRRTM, how axonal surface polarization of NRXN is achieved remains unclear. Cultured neurons expressing NLGN1 showed NLGN1transport intermediates only in the somatodendritic compartment (Rosales et al., 2005), suggesting that the polarized distribution of NLGN1 is achieved by selective trafficking to the somatodendritic compartment, as has been described for the somatodendritic protein TfR (Burack et al., 2000). A chimeric protein consisting of 32 amino acids (VVLRTACPPDYTLAMRRSPDDVPLMTPNTITM) from the intracellular cytoplasmic domain of NLGN1 (772-803) fused to the uniformly distributed protein CD8, is highly polarized to dendrites similar to WT NLGN1 (Rosales et al., 2005). This observation suggests that this motif is sufficient for dendritic polarization of NLGN1. Additionally, it has been shown indirectly that another motif (comprising the sequence 719-750) present in the cytoplasmic domain of NLGN1 mediates its postsynaptic targeting (Dresbach et al., 2004). On the other hand, expression in 
cultured neurons of a mutant of NLGN1 containing only the extracellular and the transmembrane domains produces a diffuse distribution pattern (Dresbach et al., 2004), indicating that the extracellular region is not sufficient for synaptic targeting of NLGN1. These results suggest that the cytoplasmic domain of NLGN1 controls its dendritic and synaptic insertion. Similarly, synaptic clustering of NLGN2 at inhibitory synapses requires motifs present in the region spanning amino acids 716-782 of the cytoplasmic domain of NLGN2, but not the PDZ-binding motif (Levinson et al., 2010). This finding contrasts with an observation made in flies where NLGN1, lacking the cytoplasmic domain, was found to localize to the postsynaptic membrane at the NMJ (Harris et al., 2016). Whether these contradictory findings are due to differences in NLGN1 trafficking between different species is not clear. Despite the conflicting results, these observations suggest that synaptic targeting of NLGNs is independent of: i) trans-synaptic interactions and ii) the PDZ-binding motif. Whether the amino acid sequences 719-750 (Dresbach et al., 2004) and 772-803 (Rosales et al., 2005) of NLGN1, when fused to a uniformly distributed protein, are capable of reconstituting all trafficking steps required to direct the fusion protein to postsynaptic sites has not been tested yet. Similarly, the identity of their potential binding proteins is unknown.

Even though intracellular NRXN1-positive vesicles could be detected in dendrites and axons (Fairless et al., 2008; Neupert et al., 2015), axonal surface levels of NRXN1 were at least two- to three-fold higher compared to somatic and dendritic surface levels (Fairless et al., 2008), indicating that NRXN1 exhibits polarized targeting towards the axon. Expression of a NRXN1 $1 \alpha$ mutant lacking its extracellular region showed no differences in trafficking compared to WT NRXN1a (Fairless et al., 2008), indicating that the intracellular domain is sufficient to promote axonal targeting of NRXN1 $\alpha$. In fact, fusion to the NRXN cytoplasmic domain has been used as an experimental strategy to target proteins of interest, such as synaptic reporters or ion channels, to presynaptic sites (Kim et al., 2011; Stachniak et al., 2014). Although there is evidence for a role of the cytoplasmic PDZ-binding motif in mediating ER exit (Fairless et al., 2008, discussed previously), motifs for axonal polarization of NRXN still need to be described.

In order to investigate the role of the cytoplasmic domain in the synaptic clustering of the LRRTM family of synaptogenic CAMs (Laurén et al., 2003; Linhoff et al., 2009), a cytoplasmic domain deletion mutant of LRRTM2 lacking the last 55 residues (LRRTM2 $\triangle 55$ ) was expressed in cultured neurons. This deletion abolished the synaptic clustering and the dendritic polarization of LRRTM2, resulting in a non-polarized diffuse signal along the neuronal surface (Linhoff et al., 2009). This has been confirmed for the other family members LRRTM1, LRRTM3 and LRRTM4 (Minatohara et al., 2015). Within this 55-residue long domain resides a PDZ-binding domain, but the deletion of this domain did not abolish the clustering of LRRTM2 at postsynaptic sites (Linhoff et al., 2009; Minatohara et al., 2015). This result indicates that the 55 residue portion of the cytoplasmic domain of LRRTM2, but not its PDZ-binding motif, is 
required for postsynaptic clustering. Further attempts to identify the responsible motif within this region led Doi and colleagues to an XGxC motif, YGQC in LRRTM2, that controls efficient synaptic clustering of LRRTM proteins (Minatohara et al., 2015).

\section{Surface diffusion}

After insertion at the cell surface, membrane proteins can be redistributed via lateral diffusion. The localization and surface dynamics of NLGN1 (Biermann et al., 2014; Chamma et al., 2016), LRRTM2 (Chamma et al., 2016) and NRXN (Biermann et al., 2014; Chamma et al., 2016; Fu and Huang, 2010; Neupert et al., 2015) were analysed in cultured slices and neurons. NLGN1 expressed in cultured slices exhibits high diffusion rates, although lower than NRXN1 $\beta$ (Biermann et al., 2014). Analysis of the trajectories of synaptic NLGN1 molecules showed that the diffusion coefficient of mobile NLGN1 strongly decreased within postsynaptic spines, whereas the immobile population increased (Biermann et al., 2014). In contrast, outside synapses, NLGN1 was significantly more mobile (Biermann et al., 2014). FRAP experiments in cultured neurons confirmed the high dynamics of NLGN1 at the membrane (Chamma et al., 2016). Curiously, LRRTM2, which competes with NLGN1 for binding to presynaptic NRXN (de Wit et al., 2009; Ko et al., 2009a; Siddiqui et al., 2010), showed a lower diffusion coefficient (Chamma et al., 2016). This result indicates that despite binding to the same presynaptic receptor, LRRTM2 seems more stable at the synapse. The cause of this difference is still unclear.

In cultured slices, NRXN1 $\alpha$ expressed in parvalbumin (PV)-positive interneurons was found to localize diffusely along the axon shaft, motile filopodia and presynaptic boutons, whereas NRXN1 $\beta$ was restricted to presynaptic boutons (Fu and Huang, 2010). This pattern of NRXN1 $\beta$ localization, showing enrichment at presynaptic boutons, was found to be dependent on binding to postsynaptic partners (Fu and Huang, 2010). Similarly, NRNX1 $\beta$ also shows higher enrichment at excitatory synapses than NRNX1a (Neupert et al., 2015). In contrast to the findings in cultured neurons, where NRXN-positive vesicles prominently fuse at extrasynaptic sites (Neupert et al., 2015), in PV interneurons intracellular pools of NRXN are specifically transported to presynaptic terminals, where they are delivered to the cell surface (Fu and Huang, 2010). Using fluorescent recovery after photobleaching (FRAP) experiments, synaptic levels of NRXN1 $\beta$ were found to be regulated by continuous exocytosis and endocytosis. The rapid dynamics of synaptic NRXN1 $\alpha$, on the other hand are not only controlled by continuous exocytosis and endocytosis but also by lateral diffusion (Fu and Huang, 2010). These findings agree with results in cultured neurons demonstrating that NRXN1 $\alpha$ exhibits a higher surface mobility compared to NRXN1 $\beta$ (Neupert et al., 2015). This might account for the synaptic enrichment of NRXN1 $\beta$ compared to NRXN1 $\alpha$. Fu and Huang 
hypothesized that NRXN1 $\alpha$ and NRXN1 $\beta$ mediate different aspects of GABAergic synapse formation. The dynamic lateral diffusion of $N R X N 1 \alpha$ along the axon shaft might serve as an initial exploratory mechanism to search for new potential postsynaptic partners. NRXN1 $\beta$, which is restricted to the nascent presynaptic boutons, can further stabilize newly formed transsynaptic interactions, in a GABAergic synaptic transmission-dependent manner. These observations suggest that a combination of intracellular transport, fusion events at synaptic and extrasynaptic sites and distribution via lateral diffusion are responsible for synaptic targeting of NRXNs. Overall, the high surface mobility exhibited by these molecules is a surprising finding given the fact that they engage in trans-synaptic cell adhesion.

\section{Neuronal activity}

Neuronal activity is a major determinant of the dynamic trafficking of membrane proteins residing at the synapse (Choquet and Triller, 2013), including synaptogenic CAMs. In particular, synaptic activity has been shown to control the surface and synaptic expression of CAMs by regulating membrane vesicle trafficking, surface mobility, posttranslational modification and proteolytic processing.

\section{Membrane vesicle trafficking and surface mobility}

Neuronal activity influences the kinetics of NLGN- and NRXN-positive vesicles. In particular, an increase in synaptic activity reduced the speed of NLGN1-positive vesicles and increased the number of NLGN1-positive clusters (Gutiérrez et al., 2009). On the other hand, a reduction in synaptic activity increased the number of mobile NLGN1-positive clusters (Schapitz et al., 2010), thus suggesting that synaptic activity leads to an increase in stabilized NLGN protein clusters present on the dendritic surface available for trans-synaptic interactions. In contrast, TTX treatment (to prevent action potentials) reduced the velocity of NRXN1-positive vesicles, whereas $\mathrm{KCl}$ treatment increased their velocity in the axon (Neupert et al., 2015). Curiously, dendritic NRXN1-positive vesicles were not affected by changes in neuronal activity (Neupert et al., 2015). Altogether, these observations indicate that synaptic activity bidirectionally modifies the kinetics of membrane vesicle trafficking of NLGN and NRXN. Finally, TTX treatment increased the recovery rate of NRXN1 $\beta$ fluorescence in PV neurons after photobleaching (Fu and Huang, 2010). The effect of TTX was mimicked by pharmacological and genetic blocking of GABAergic synaptic transmission (Fu and Huang, 2010), suggesting that GABAergic synaptic activity increases the stability of membrane-inserted NRXN1 $\beta$.

Neuronal activity has been also shown to control surface levels of NLGN. In particular, surface levels of NLGN1/3 in cultured neurons and in acute slices are bidirectionally regulated by changes in synaptic strength (Schapitz et al., 2010). Combination of DHPG treatment (to 
induce chemical long-term depression (CLTD), Huber et al., 2001; Palmer et al., 1997) with nocodazole prevented the reduction in dendritic surface levels of NLGN1/3 triggered by LTD (Schapitz et al., 2010). This finding suggests that microtubule-mediated transport is required for depletion of surface NLGN upon decreased synaptic activity. By performing a series of coimmunoprecipitations in vesicle-enriched brain fractions followed by mass spectrometry (MS), the authors identified the dynein intermediate chain (DIC) as part of a PSD-95-NLGN1/3 protein complex (Schapitz et al., 2010), which led them to hypothesize that the NLGN cytoplasmic domain binding partner PSD-95 could link NLGN to a dynein motor complex, as has been suggested for other synaptic cargo and scaffold proteins (Heisler et al., 2014; Hoogenraad et al., 2005; Jeyifous et al., 2009; Schapitz et al., 2010; Setou et al., 2000, 2002; Terauchi et al., 2015). Live-cell imaging experiments in cultured neurons showed co-transport of NLGN1, PSD-95 and DIC (Schapitz et al., 2010). Confirming their hypothesis, NLGN1/3 and PSD-95 accumulated at synapses in transgenic mice overexpressing dynamitin (Schapitz et al., 2010), which inhibits dynein-mediated retrograde transport (LaMonte et al., 2002). Additionally, either interference with NLGN1-PSD-95 binding, or blocking of dynein-mediated retrograde transport, decreased internalization of NLGN1 in cultured neurons (Schapitz et al., 2010). Altogether, these observations indicate that microtubule-mediated transport underlies changes in synaptic levels of NLGN triggered by changes in synaptic activity. How synaptic activity regulates NLGN-PSD-95-dynein binding to remove NLGN at synaptic sites remains to be explored.

Chemical LTD has also been used to look at activity-dependent changes in the surface distribution of SynCAM1, a member of the Ig-domain containing superfamily of CAMs. Induction of CLTD in cultured neurons increased the area of SynCAM1 synaptic puncta (Perez de Arce et al., 2015). Yet, how synaptic depression increases the synaptic recruitment of SynCAM1 is still unknown.

\section{Phosphorylation}

In addition to activity-dependent microtubule-mediated transport, surface levels of NLGN1 were also shown to be modulated by activity-dependent CAMKII-mediated phosphorylation (Bemben et al., 2014). In cultured neurons, NLGN1 phosphorylation at T739 in its intracellular tail was modulated by synaptic activity: treatment with the GABAA receptor antagonist bicuculline (to increase network activity) augmented NLGN1 phosphorylation, which was blocked by pre-treatment with antagonists of ionotropic glutamate receptors (Bemben et al., 2014). To manipulate synaptic activity in vivo, the authors used a well-established dark-rearing paradigm, which involves depriving mice of light for 5 days and re-exposing them to light for 2 hours (dark rearing plus light exposure). Dark-reared mice showed a reduction in T739 phosphorylation, whereas dark-reared mice that were subjected to 2 hours of light rearing 
exhibited an increase in T739 phosphorylation (Bemben et al., 2014). These observations indicate that changes in synaptic activity in vivo are able to bidirectionally modulate NLGN1 T739 phosphorylation. The dendritic surface expression of a phosphodeficient NLGN1 T739A mutant was diminished in cultured neurons compared to WT NLGN1 (Bemben et al., 2014). While bicuculline treatment, which increases NLGN1 T739 phosphorylation, augmented NLGN1 surface expression. Yet, activity-driven increase in NLGN1 surface expression was suppressed in the T739A mutant (Bemben et al., 2014). These results show that synaptic activity-driven T739 phosphorylation regulates NLGN1 surface trafficking. However, its mechanistic underpinnings remain unexplored.

\section{Proteolytic processing}

Activity-dependent cleavage of NLGN also controls its synaptic surface levels. NLGN1 undergoes proteolytic processing: ADAM10 (Suzuki et al., 2012) and/or MMP9 (Peixoto et al., 2012) metalloproteases cleave NLGN1 at the juxtamembrane stalk region, generating a secreted N-terminal fragment (NTF) and a membrane-tethered CTF, which is further cleaved by $\gamma$-secretase activity releasing the NLGN1 intracellular domain (ICD) (Peixoto et al., 2012; Suzuki et al., 2012). Increased synaptic activity augmented NLGN1-NTF levels, whereas decreased synaptic activity reduced the production of NLGN1-NTF levels (Peixoto et al., 2012; Suzuki et al., 2012). This has been validated in vivo (Peixoto et al., 2012; Suzuki et al., 2012). In addition, NLGN1-NTF production was also augmented when cultured neurons were treated with medium containing soluble NRXN (Suzuki et al., 2012). Thus, NLGN1 shedding can be induced both by neuronal activity and ligand binding. Importantly, proteolytic processing of NLGN1 has also been shown to occur at the cell surface and synaptic level, thus controlling its surface and synaptic expression (Peixoto et al., 2012; Suzuki et al., 2012). Consistently, stimulation of a single dendritic spine with local glutamate uncaging induced rapid loss of spine FL NLGN1, without affecting the fluorescence intensity of NLGN1 in the neighbouring dendritic shaft (Peixoto et al., 2012), indicating that NLGN1 proteolytic processing occurs only in activated dendritic spines. Overall these observations suggest that activity-induced shedding of NLGN1 acts as a local homeostatic mechanism to control synaptic levels of NLGN1, which has profound presynaptic and postsynaptic functional consequences (Peixoto et al., 2012; Suzuki et al., 2012). It is worth noting that induced-NLGN1 cleavage caused rapid loss of NRXN $\beta 1$ from opposing presynaptic terminals (Peixoto et al., 2012).

NRXNs also undergo proteolytic processing (Borcel et al., 2016; Bot et al., 2011; Saura et al., 2011; Suzuki et al., 2012; Tong et al., 2017), but in this case the physiological function of its cleavage and which proteases mediate their processing are still under debate. Incubation of cultured neurons with $\mathrm{KCl}$ and glutamate led to an increase in endogenous NRXN-CTF levels (Bot et al., 2011), indicating that NRXN cleavage is also regulated by synaptic activity. 
Furthermore, levels of NRXN-CTF were also increased in synaptosomal and presynaptic fractions prepared from cortices of double KO mice for presenilins (PS) (Saura et al., 2011), the catalytic components of the $\gamma$-secretase complex. This finding suggests that synaptic levels of NRXNs are also regulated by proteolytic processing. Confirming this hypothesis, accumulation of synaptic FL NRXN was augmented in cultured neurons expressing a defective mutant of PS1 as compared to WT PS1-expressing neurons (Saura et al., 2011). A recent study shed light on the physiological relevance of NRXN proteolytic processing. Shedding of NRXN1 by the protease ADAM10 at the NMJ in C. elegans, where NRXN1 is post-synaptic, results in retrograde inhibition of neurotransmitter release by binding to and inhibiting presynaptic calcium channels (Tong et al., 2017). Altogether, the experiments described in this section suggest that synaptogenic CAMs undergo dynamic changes in their trafficking and surface distribution in response to synaptic activity.

\section{Endosome-associated sorting stations}

Following biosynthetic transport and arrival at the plasma membrane, many membrane proteins, including neurotransmitter receptors and guidance receptors, undergo endocytosis and gather in endosomes (Yap and Winckler, 2012). Upon entering the endosomal network, two major sorting decisions are made that determine the fate of internalized cargo. Cargo proteins are either sorted for degradation in lysosomes or may escape the degradative outcome, by being retrieved along endosomal subdomains for recycling back to the plasma membrane or the trans-Golgi network (TGN) (Hsu et al., 2012). The endosomal network thus constitutes a fundamental hub in the trafficking of neuronal membrane proteins, thereby maintaining synaptic protein homeostasis. Recently, several major endosome-associated sorting stations have been identified, ensuring faithful endosome-to-plasma membrane recycling of CAMs, while preventing their lysosomal degradation.

Retromer is an endosome-localized multi-subunit complex initially identified in Saccharomyces cerevisiae that was found to be required for the retrieval of the vacuolar protein sorting 10 protein (VPS10P) from endosomes to the TGN (Seaman et al., 1998). Despite its well-established role in mediating endosome-to-TGN retrieval (Bonifacino and Hurley, 2008), recent studies have uncovered a key function for retromer in the recycling of membrane proteins from endosomes to the plasma membrane (Seaman, 2012). Retromer is composed of two subcomplexes: a VPS26-VPS29-VPS35 core heterotrimer and a membranedeforming heterodimer consisting of sorting nexins (SNX1, SNX2, SXN5 or SNX6) that contain a Bin, Amphiphysin and Rvs (BAR) domain (Burd and Cullen, 2014; Gallon and Cullen, 2015). It is now appreciated that in heterologous cells there exist three structurally and functionally distinct mammalian retromer complexes depending on the SNXs that associate with the core heterotrimer. The core heterotrimer can interact with members of the SNX-BAR subfamily 
(SNX1, SNX2, SXN5 and SNX6), the SNX-PH subfamily (SNX3) or the SNX-FERM subfamily (SNX17, SNX27 and SNX31). The canonical SNX-BAR-retromer and SNX3-retromer both mediate endosome-to-TGN trafficking, but constitute distinct, cargo-specific pathways (Bonifacino and Rojas, 2006; Harterink et al., 2011). SNX27-retromer on the other hand plays a key role in endosome-to-plasma membrane recycling of the $\beta 2$ adrenergic receptor (Choy et al., 2014; Lauffer et al., 2010; Steinberg et al., 2013; Temkin et al., 2011), AMPA receptors (Choy et al., 2014; Hussain et al., 2014; Loo et al., 2014) and the potassium channel Kir3.3 (Balana et al., 2011). SNX27 acts as a cargo adaptor by binding to PDZ ligands or NPXYNxxY-based sorting motifs via its PDZ-binding domain and FERM-domain, respectively, thereby promoting retromer-mediated retrieval and recycling of cargo proteins (Gallon and Cullen, 2015). Quantitative SILAC-based proteomic surface analysis of VPS35-deficient HeLa cells revealed that more than 150 membrane proteins were dependent on the core heterotrimer for their endosome-to-plasma membrane recycling. Of these, more than 80 required the presence of SNX27 for their surface expression, indicating that the core heterotrimer is able to recycle cargo proteins independently of SNX27, arguing in favor of the proposed function of SNX27 as a cargo adaptor. Furthermore, loss of VPS35 or SNX27 led to cargo missorting and enhanced degradation in lysosomes (Steinberg et al., 2013). Among the membrane proteins that exhibited reduced surface expression in VPS35- or SNX27-depleted cells, many CAMs were identified, including the LRR synaptogenic CAMs, synaptic adhesion-like molecule 3 (SALM3) and Slit- and Trk-like proteins (SLITRKs), as well as receptor protein tyrosine phosphatase (RPTPs) (Steinberg et al., 2013). Using transgenic mice expressing tandem affinity purification (TAP)-tagged NLGN2 followed by MS-based detection of purified NLGN2 complexes, NLGN2 was found to associate with VPS35. Furthermore, endocytosed NLGN2 was present in VPS35-containing vesicle-like structures throughout neuronal dendrites in culture (Kang et al., 2014). It thus seems likely that NLGN2 depends on retromer-mediated recycling to maintain its surface levels.

Another major endosome-associated sorting station that orchestrates cargo recycling and prevents lysosomal missorting was recently identified (McNally et al., 2017). Retriever is structurally and functionally analogous to retromer and consists of a VPS29-C16orf62-DSCR3 core heterotrimer that associates with the cargo adaptor SNX17 (McNally et al., 2017), previously implicated in the retromer-independent surface recycling and prevention of lysosomal degradation of $\alpha$ - and $\beta$-integrins. Using the same quantitative SILAC-based proteomic surface analysis as mentioned before, more than 220 membrane proteins were found to have reduced surface expression in SNX17-depleted HeLa cells. Among these, many CAMs were again identified, including RPTPS, SLITRK4, fibronectin leucine-rich repeat transmembrane protein (FLRT2), and EphB2. Since the aforementioned studies were 
performed in heterologous cells, it remains to be determined whether these major endosomeassociated sorting operate in a similar manner in neurons.

SorCS1, a VPS10P-domain containing sorting receptor that localizes to early and recycling endosomal compartments, was recently identified as a global regulator of synaptic receptor trafficking in neurons (Savas et al., 2015). Quantitative proteomic analysis of surface proteins in cultured neurons and of synaptosomes from Sorcs $1 \mathrm{KO}$ mice revealed a reduction in the surface expression and synaptic abundance of key glutamate receptor and adhesion proteins, most notably NRXNs and NLGNs, in the absence of SorCS1 (Savas et al., 2015). These findings are strikingly reminiscent of the changes in receptor surface expression observed when components of the retromer or retriever complex are depleted in heterologous cells. Interestingly, SorCS1 has been demonstrated to exist in a complex with VPS35, one of the core components of the retromer complex (Lane et al., 2010, 2013). Via its interaction with the retriever and retromer complexes, SorCS1 links to key intracellular sorting pathways that regulate the trafficking of surface receptors destined for recycling.

\section{Aberrant trafficking of synaptogenic CAMs in neurodevelopmental disorders}

Several mutations in synaptogenic CAMs that influence their folding and biosynthetic maturation have been identified in patients with neurodevelopmental disorders such as autism spectrum disorder (ASD) or schizophrenia, underscoring the importance of correct protein trafficking for normal brain function (Table 2). Among the NLGN family members, NLGN3 and NLGN4 were initially found to be strongly associated with ASD, with less evidence for the relevance of NLGN1 and NLGN2 (Jamain et al., 2003). A more recent study however, shed light on the functional significance of NLGN1 variants in the etiology of ASD (Nakanishi et al., 2017). An R451C substitution in NLGN3 that was originally identified in two siblings diagnosed with ASD (Jamain et al., 2003), which alters a conserved residue in the extracellular ChE-like domain, represents the most well-characterized NLGN mutation to date. Rather than disrupting the binding to its presynaptic partner NRXN, the R451C substitution has been shown to compromise the intracellular trafficking of NLGN3. When expressed in heterologous cells and in cultured neurons, most NLGN3 R451C is retained in the ER, diverted to the proteasome for degradation and as a consequence, fails to reach the dendritic surface. An altered glycosylation pattern, an increased susceptibility to protein digestion and a strong association with ER stress chaperones indicate that the R451C substitution impairs folding of NLGN3 (Chih et al., 2004; Comoletti et al., 2004; De Jaco et al., 2008, 2010a, 2010b). Consistent with an accumulation of misfolded proteins in the ER, De Jaco and colleagues demonstrated that expression of NLGN3 R451C in PC12 cells led to the activation of the unfolded protein 
response (UPR) (Ulbrich et al., 2016), a series of protective mechanism that aims to restore to normal ER function (Hetz et al., 2015). Corroborating the in vitro findings, knockin (KI) mice carrying the R451C substitution showed a 90\% reduction in NLGN3 protein levels in the forebrain (Tabuchi et al., 2007). These mice exhibit synaptic defects and behavioural phenotypes reminiscent of ASD (Tabuchi et al., 2007). An R87W substitution in NLGN4, identified in two autistic siblings, represents another mutation of which the functional consequences have been investigated (Zhang et al., 2009). This substitution similarly disrupts a conserved residue in the extracellular ChE-like domain and its expression in heterologous cells lead to a retention in the ER that was accompanied by an altered glycosylation pattern (Zhang et al., 2009). Accordingly, the R87W substitution impeded NLGN4 transport to the surface of non-neuronal cells and cultured neurons, and blocked its ability to induce synapse formation (Zhang et al., 2009). Three missense mutations residing in the extracellular ChE-like domain (P89L, L269P, and G297E), and one in the cytoplasmic tail (H795Y) of NLGN1 were recently detected in patients with ASD (Nakanishi et al., 2017). When expressed in heterologous cells, all variants located in the extracellular ChE-like domain exhibited an increased retention in the ER and a reduced expression at the cell surface (Nakanishi et al., 2017). Interestingly, the H795Y variant showed reduced surface expression without any abnormal subcellular localization. Instead, NLGN1 H795Y was found to be more susceptible to ectodomain cleavage (Nakanishi et al., 2017), which has been demonstrated to result in a loss of its expression at synaptic sites, as discussed above. Consequently, all four variants failed to reach the cell surface when expressed in cultured neurons and lead to the impairment of spine formation (Nakanishi et al., 2017). The authors generated NLGN1 P89L KI mice and found a $60 \%$ reduction in NLGN1 protein levels across various brain regions, in agreement with their in vitro findings (Nakanishi et al., 2017). Furthermore, these mice displayed abnormal social behaviour, recapitulating some of the symptoms of autistic patients (Nakanishi et al., 2017).

Recently, Um and colleagues undertook a similar systematic characterisation of the biochemical and cell-biological properties of various SLITRK missense mutations previously found to be associated with schizophrenia or obsessive-compulsive disorder (OCD) (Kang et al., 2016). When expressed in heterologous cells, SLITRK1 (N400I and T418S) and SLITRK4 (V206I and 1578V) accumulated in the ER and Golgi compartment, exhibited an aberrant glycosylation pattern, and showed reduced surface expression (Kang et al., 2016). When expressed in cultured neurons, these mutants similarly displayed an altered subcellular localization pattern and a strong impairment in dendritic surface targeting (Kang et al., 2016). As a result, all four variants lacked synaptogenic activity and failed to increase synapse density (Kang et al., 2016). Altogether, these studies indicate that disease-associated mutations in CAMs impact their trafficking, resulting in synaptic and behavioural defects. 


\section{Perspectives}

To grasp how a protein of interest is trafficked, a detailed understanding and systematic identification of the specific components and sorting signals involved in vesicle budding, transport and fusion is needed. In this regard, our understanding of the molecular mechanisms that govern surface targeting of synaptogenic CAMs is far from complete, with most of the studies focusing on the NRXN-NLGN complex. Genetic mutations in their extracellular or cytoplasmic domains that prevent CAMs from reaching the neuronal surface are associated with various neurodevelopmental disorders. Moreover, mutations in the endosome-associated sorting genes SORCS1 and VPS35 have been linked to a broader range of neurological diseases (Christoforou et al., 2011; Grupe et al., 2006; Laumet et al., 2010; Li et al., 2008; Liang et al., 2009; Lionel et al., 2011; Ollila et al., 2009; Reitz et al., 2011; Sanders et al., 2012; Small and Petsko, 2015) underscoring the importance of correct protein trafficking for normal brain function. Ultimately, a better understanding of the molecular mechanisms that ensure faithful delivery of cargo proteins to the synapse will provide essential insights and novel avenues for therapeutic interventions.

The highly compartmentalized nature of neurons and their regionally specialized adaptations to the secretory route pose a major challenge in elucidating the trafficking itinerary that governs synaptic targeting of membrane proteins. In addition to the conventional ERERGIC-Golgi-plasma membrane delivery route, recent reports have identified non-canonical trafficking pathways in which AMPA receptors and NLGN1 reach the dendritic surface without traversing through the Golgi compartment (Bowen et al., 2017; Mikhaylova et al., 2016). Instead, ER exit and accumulation in ERGICs was shown to be followed by direct shuttling to recycling endosomes (REs) before reaching the dendritic surface (Bowen et al., 2017). Alternatively, trafficking to REs from ERGICs might occur via an intermediate compartment, termed Golgi satellites, which are structurally and functionally different from earlier described Golgi outposts (Mikhaylova et al., 2016). These findings indicate that the organization and compartmentalization of the secretory system is much more complex than initially envisioned. The importance of these non-canonical trafficking pathways for neuronal physiology and the CAMs that are routed via them remain unknown. Furthermore, while dendritic CAMs are delivered in a direct polarized fashion, polarized axonal trafficking of CAMs is much less understood. Another caveat is that much of our understanding of the trafficking of CAMs derives largely from in vitro studies in heterologous cells, and conflicting results have often been reported. Future work should address the apparent discrepancies and the relevance of these findings in neuronal cells. Finally, while we are beginning to appreciate the role of neuronal activity in the extracellular proteolytic cleavage of CAMs, if and how neurotransmission influences trafficking along the secretory and endosomal pathway remains largely unexplored. 
The advent of cutting-edge in vivo live-cell imaging techniques and super-resolution microscopy (Villa et al., 2016; Zhang et al., 2015), in combination with systems that enable spatiotemporal control over cargo trafficking (Boncompain et al., 2012; Mondal et al., 2017), provide unparalleled opportunities to unravel the diversity of secretory routes and to decipher the trafficking pathways that govern synaptic targeting of CAMs. In addition, advances in proteomics (Loh et al., 2016; Uezu et al., 2016) and the ability to isolate distinct subcellular compartments (Drissi et al., 2013; Tharkeshwar et al., 2017) should allow for the identification of novel CAM-interacting proteins in a compartment-specific manner. Lastly, the emergence of convenient genome-editing tools, in particular those based on the CRISPR-Cas system, allow fast in vivo gene editing in the brain (Heidenreich and Zhang, 2016). Together, these techniques hold promise for accelerating our understanding of the molecular determinants involved in the trafficking of CAMs.

\section{Acknowledgements}

We thank Gabriele Marcassa for assistance in preparing figures. Work in the authors' lab on synaptic adhesion molecule trafficking is supported by a European Research Council Starting Grant (\#311083), an FWO Odysseus grant, FWO Project grants G094016N and G0C4518N, ERANET NEURON 2015, and KU Leuven Methusalem grant. L.F.R is supported by a FWO Postdoctoral fellowship (12N0316N). 


\section{Box 1. Scaffold-mediated clustering of synaptogenic CAMs}

After reaching the neuronal surface, the synaptic balance of CAMs is influenced by their interactions with scaffold proteins. Several reports suggest that overexpression of synaptic scaffold proteins alters the synaptic clustering of NLGNs. For instance, overexpression of PSD95 increased the synaptic clustering of NLGN1 (Graf et al., 2004; Prange et al., 2004), NLGN2 (Levinson et al., 2005), NLGN3 (Graf et al., 2004; Levinson et al., 2005; Prange et al., 2004) and NLGN4 (Graf et al., 2004). Moreover, overexpression of S-SCAM induced synaptic clustering of NLGN1 (lida et al., 2004). Synaptic scaffold proteins also dictate the specific synaptic localization of NLGNs. NLGN2 and NLGN4 are found exclusively at inhibitory synapses (Hoon et al., 2011; Varoqueaux, 2004). On the other hand, NLGN1 is primarily targeted to excitatory synapses (Song et al., 1999), while NLGN3 is found at both synapse types (Budreck and Scheiffele, 2007). Knockdown (KD) of PSD-95 shifts NLGN1 (Gerrow et al., 2006) and NLGN3 (Levinson et al., 2010) from excitatory to inhibitory synapses and the overexpression of PSD-95 shifts the localization of NLGN2 from inhibitory to excitatory synapses (Graf et al., 2004; Levinson et al., 2005). Consistently, KD of gephyrin increases the proportion of NLGN2 present at excitatory synapses, whereas the depletion of PSD-95 results in the opposite phenotype (Levinson et al., 2010). Phosphorylation has been shown to modulate the binding of NLGNs to synaptic scaffold proteins, thereby influencing their synaptic localization (Antonelli et al., 2014; Giannone et al., 2013). Nrxn1 $\beta$ binding to NLGN1 stimulates phosphorylation at Y782, thereby enhancing NLGN1-PSD-95 binding, shifting NLGN1 away from interacting with gephyrin (Giannone et al., 2013). Additionally, NLGN2 phosphorylation at S714 negatively regulates NLGN2-gephyrin binding (Antonelli et al., 2014). 


\section{Figures and Figure legends}

(A)

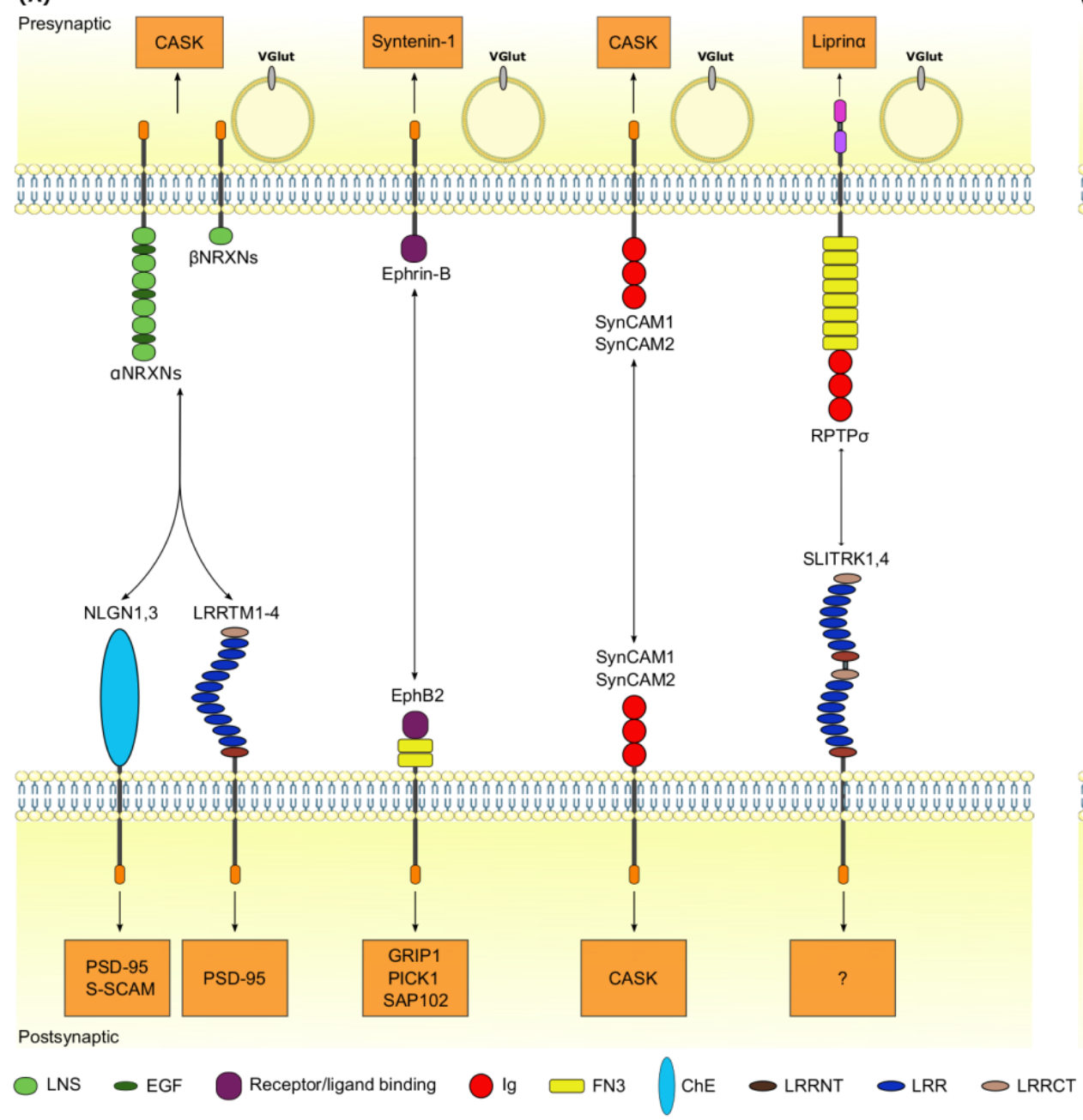

(B)

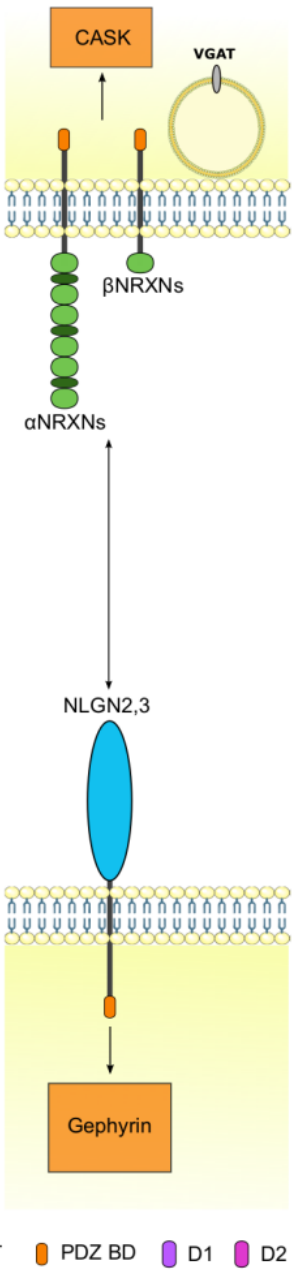

Figure 1. Domain organization and interactions of a selected set of synaptogenic CAMs, as discussed in this review. (A) At excitatory synapses, postsynaptic leucine-rich repeat transmembrane neuronal proteins 1-4 (LRRTM1-4) and neuroligins 1-3 (NLGN1-3) bind to presynaptic $\alpha$ - (long) and $\beta$ - (short) neurexins (NRXNs). Postsynaptic Slit- and Trk-like proteins 1 and -4 (SLITRK1 and SLITRK4) interact with the presynaptic leukocyte common antigenrelated (LAR) family receptor protein tyrosine phosphatase $\sigma$ (RPTP $\sigma$ ). SynCAM1 and SynCAM2 form homo- and heterophilic complexes across the synaptic cleft. In addition to these classical CAMs, receptor tyrosine kinases were found to be synaptogenic as well. Postsynaptic EphB2 induces presynaptic differentiation via binding to its cognate ligand ephrinB2. (B) Postsynaptic NLGN2 and NLGN3 regulate inhibitory synapse formation via binding to $\alpha-$ and $\beta-N R X N s$. Interacting scaffolding proteins are indicated in orange boxes. Domain abbreviations: LNS, laminin- $\alpha$ /neurexin/sex-hormone-binding globulin; EGF, epidermal growth factor-like; Ig, immunoglobulin-like; FN3, fibronectin type III; ChE, cholinesterase-like; LRRNT, 
LRRCT, LRR N- and C-terminal flanking domains; PDZ-BD, postsynaptic density protein (PSD95), Drosophila disc large tumor suppressor (DlgA), and zonula occludens-1 protein (zo1) (PDZ)-binding domain; D1, D2, membrane-proximal (catalytically active) and -distal (inactive) tyrosine phosphatase domains. 


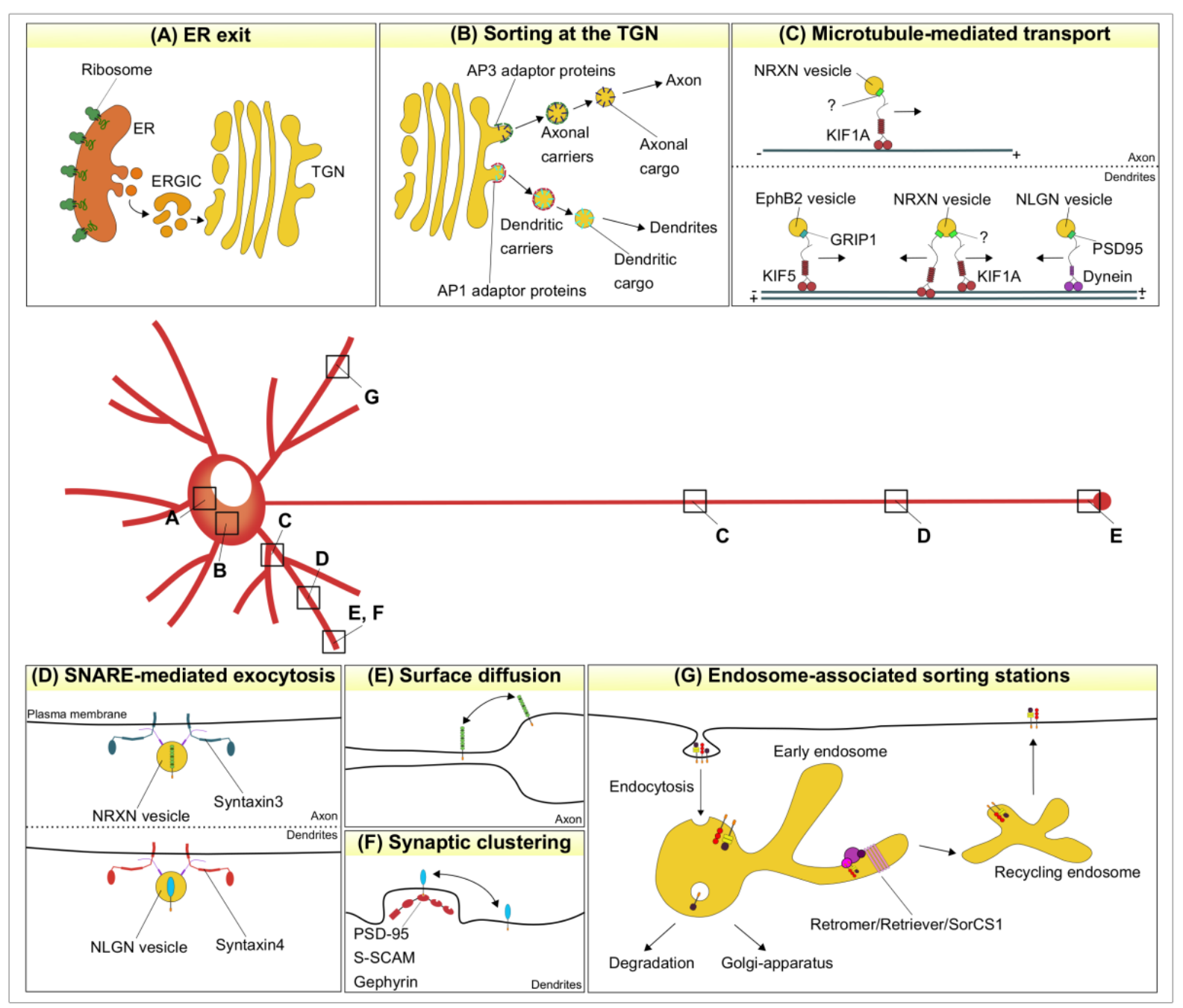

Figure 2. A series of sequential trafficking events along the secretory pathway, as well as post-secretory mechanisms regulate the surface and synaptic expression of CAMs.

(A) Proteolytic cleavage, dimerization and PDZ domain-interactions of CAMs (not depicted) have been shown to facilitate vesicle budding from the ER. (B) AP-3 and AP-1 occupy adjacent domains at the Golgi-apparatus, where they sort axonal and dendritic CAMs into distinct pools of vesicles that are selectively trafficked to their respective destinations. This polarized trafficking is achieved via specific binding affinities of dileucine- and tyrosine-based sorting motifs to AP-3 and AP-1. (C) Transport vesicles emanating from the TGN associate with distinct motor and adaptor proteins to selectively regulate anterograde or retrograde microtubule-mediated transport along the axon and dendrites. Note that NRXN is transported bidirectionally along dendrites. (D) Syntaxin3 and syntaxin4 mediate the selective fusion of NRXN and NLGN-containing transport vesicles with the axonal and dendritic plasma membrane, respectively. (E) Once CAMs are inserted at the appropriate plasma membrane location, which might occur at synaptic sites or extrasynaptic sites, they can be redistributed via lateral diffusion. (F) Binding to postsynaptic scaffold proteins promotes synaptic clustering 
of NLGNs. (G) Following endocytosis, CAMs enter the endosomal pathway. Endosomeassociated sorting stations, such as retromer, retriever, and SorCS1, promote endosome-toplasma membrane recycling of CAMs, thus preventing their lysosomal degradation. Synaptic activity controls the surface and synaptic expression of CAMs by regulating membrane vesicle trafficking, surface mobility and proteolytic processing of CAMs. 
Table 1 - Experimentally validated motifs/residues involved in the trafficking of synaptogenic CAMs

\begin{tabular}{|c|c|c|c|}
\hline Protein & Motif/Description (sequence location) & $\begin{array}{l}\text { Trafficking } \\
\text { step }\end{array}$ & Reference \\
\hline dNLGN2 & $\begin{array}{l}\text { YPQRSGSVRGEDVPFWLGLPMSPLFPHNYTTQERQIGRLMLRYLSNFAKTGNPNQST } \\
\text { (extracellular domain) }\end{array}$ & ER exit & Tu et al., 2017 \\
\hline NLGN2 & $\begin{array}{l}\text { N691L mutation bypasses ER-retention in monomeric NLGN2 (transmembrane } \\
\text { domain) }\end{array}$ & ER exit & Poulopoulos et al., 2012 \\
\hline $\begin{array}{l}\text { NRXN1a } \\
\text { NRXN3 } \beta\end{array}$ & YYV (intracellular domain) & ER exit & $\begin{array}{l}\text { Fairless et al., } 2008 \\
\text { Gokce and Südhof, } 2013\end{array}$ \\
\hline NLGN1 & VVLRTACPPDYTLAMRRSPDDVPLMTPNTITM (intracellular domain) & $\begin{array}{c}\text { Dendritic } \\
\text { polarization }\end{array}$ & Rosales et al., 2005 \\
\hline NLGN1 & YKKDKRRHDVHRRCSPQRTTTNDLTHAPEEEI (intracellular domain) & $\begin{array}{l}\text { Postsynaptic } \\
\text { insertion }\end{array}$ & Dresbach et al., 2004 \\
\hline LRRTM2 & YGQC (intracellular domain) & $\begin{array}{l}\text { Postsynaptic } \\
\text { insertion }\end{array}$ & Minatohara et al., 2015 \\
\hline NRXN1 & $\begin{array}{l}\text { YKYRNRDEGSYHVDESRNYISNSAQSNGAVVKEKQPSSAKSANKNKKNKDKEYYV } \\
\text { (intracellular domain) }\end{array}$ & $\begin{array}{l}\text { Presynaptic } \\
\text { insertion }\end{array}$ & $\begin{array}{c}\text { Kim et al., } 2011 \\
\text { Stachniak et al., } 2014\end{array}$ \\
\hline
\end{tabular}

Table 2 - Trafficking-impairing mutations identified in synaptogenic CAMs associated with neuro-developmental disorders

\begin{tabular}{|c|c|c|c|c|}
\hline Protein & Mutation (sequence location) & Disorder & Trafficking step & Reference \\
\hline \multirow{4}{*}{ NLGN1 } & Missense mutation P89L (ChE-like domain) & ASD & ER exit & \multirow{4}{*}{ Nakanishi et al., 2017} \\
\hline & Missense mutation L269P (ChE-like domain) & ASD & ER exit & \\
\hline & Missense mutation G297E (ChE-like domain) & ASD & ER exit & \\
\hline & Missense mutation H795Y (intracellular domain) & ASD & $\begin{array}{c}\text { Increased surface } \\
\text { ectodomain shedding }\end{array}$ & \\
\hline NLGN3 & Missense mutation R451C (ChE-like domain) & ASD & ER exit & $\begin{array}{c}\text { Chih et al., } 2004 \\
\text { Comoletti et al., } 2004\end{array}$ \\
\hline NLGN4 & Missense mutation R87W (ChE-like domain) & ASD & ER exit & Zhang et al., 2009 \\
\hline \multirow{2}{*}{ SLITRK1 } & Missense mutation N400I (LRR domain) & OCD & ER exit & \multirow{4}{*}{ Kang et al., 2016} \\
\hline & Missense mutation T418S (LRR domain) & OCD & ER exit & \\
\hline \multirow{2}{*}{ SLITRK4 } & Missense mutation V206I (extracellular domain) & Schizophrenia & ER exit & \\
\hline & Missense mutation I578V (extracellular domain) & Schizophrenia & ER exit & \\
\hline
\end{tabular}




\section{References}

Antonelli, R., Pizzarelli, R., Pedroni, A., Fritschy, J.-M., Del Sal, G., Cherubini, E., Zacchi, P., 2014. Pin1-dependent signalling negatively affects GABAergic transmission by modulating neuroligin2/gephyrin interaction. Nat. Commun. 5, 5066. https://doi.org/10.1038/ncomms6066

Balana, B., Maslennikov, I., Kwiatkowski, W., Stern, K.M., Bahima, L., Choe, S., Slesinger, P.A., 2011. Mechanism underlying selective regulation of $G$ protein-gated inwardly rectifying potassium channels by the psychostimulant-sensitive sorting nexin 27. Proc. Natl. Acad. Sci. 108, 5831-5836. https://doi.org/10.1073/pnas.1018645108

Bemben, M.A., Shipman, S.L., Hirai, T., Herring, B.E., Li, Y., Badger, J.D., Nicoll, R.A., Diamond, J.S., Roche, K.W., 2014. CaMKII phosphorylation of neuroligin-1 regulates excitatory synapses. Nat. Neurosci. 17, 56-64. https://doi.org/10.1038/nn.3601

Bentley, M., Banker, G., 2016. The cellular mechanisms that maintain neuronal polarity. Nat. Rev. Neurosci. 17, 611-622. https://doi.org/10.1038/nrn.2016.100

Biederer, T., Kaeser, P.S., Blanpied, T.A., 2017. Transcellular Nanoalignment of Synaptic Function. Neuron 96, 680-696. https://doi.org/10.1016/j.neuron.2017.10.006

Biederer, T., Scheiffele, P., 2007. Mixed-culture assays for analyzing neuronal synapse formation. Nat. Protoc. 2, 670-676. https://doi.org/10.1038/nprot.2007.92

Biermann, B., Sokoll, S., Klueva, J., Missler, M., Wiegert, J.S., Sibarita, J.-B., Heine, M., 2014. Imaging of molecular surface dynamics in brain slices using single-particle tracking. Nat. Commun. 5. https://doi.org/10.1038/ncomms4024

Boncompain, G., Divoux, S., Gareil, N., de Forges, H., Lescure, A., Latreche, L., Mercanti, V., Jollivet, F., Raposo, G., Perez, F., 2012. Synchronization of secretory protein traffic in populations of cells. Nat. Methods 9, 493-498. https://doi.org/10.1038/nmeth.1928

Bonifacino, J.S., 2014. Adaptor proteins involved in polarized sorting. J. Cell Biol. 204, 7-17. https://doi.org/10.1083/jcb.201310021

Bonifacino, J.S., Hurley, J.H., 2008. Retromer. Curr. Opin. Cell Biol. 20, 427-436. https://doi.org/10.1016/j.ceb.2008.03.009

Bonifacino, J.S., Rojas, R., 2006. Retrograde transport from endosomes to the trans-Golgi network. Nat. Rev. Mol. Cell Biol. 7, 568-579. https://doi.org/10.1038/nrm1985

Borcel, E., Palczynska, M., Krzisch, M., Dimitrov, M., Ulrich, G., Toni, N., Fraering, P.C., 2016. Shedding of neurexin $3 \beta$ ectodomain by ADAM10 releases a soluble fragment that affects the development of newborn neurons. Sci. Rep. 6. https://doi.org/10.1038/srep39310

Bot, N., Schweizer, C., Ben Halima, S., Fraering, P.C., 2011. Processing of the Synaptic Cell Adhesion Molecule Neurexin-3 $\beta$ by Alzheimer Disease $\alpha$ - and $\gamma$-Secretases. J. Biol. Chem. 286, 2762-2773. https://doi.org/10.1074/jbc.M110.142521

Bowen, A.B., Bourke, A.M., Hiester, B.G., Hanus, C., Kennedy, M.J., 2017. Golgiindependent secretory trafficking through recycling endosomes in neuronal dendrites and spines. eLife 6. https://doi.org/10.7554/eLife.27362

Braakman, I., Hebert, D.N., 2013. Protein Folding in the Endoplasmic Reticulum. Cold Spring Harb. Perspect. Biol. 5, a013201-a013201. https://doi.org/10.1101/cshperspect.a013201

Budreck, E.C., Scheiffele, P., 2007. Neuroligin-3 is a neuronal adhesion protein at GABAergic and glutamatergic synapses: Synaptic localization of neuroligin-3. Eur. J. Neurosci. 26, 1738-1748. https://doi.org/10.1111/j.1460-9568.2007.05842.x

Burack, M.A., Silverman, M.A., Banker, G., 2000. The Role of Selective Transport in Neuronal Protein Sorting. Neuron 26, 465-472. https://doi.org/10.1016/S08966273(00)81178-2

Burd, C., Cullen, P.J., 2014. Retromer: A Master Conductor of Endosome Sorting. Cold Spring Harb. Perspect. Biol. 6, a016774-a016774. https://doi.org/10.1101/cshperspect.a016774 
Chamma, I., Letellier, M., Butler, C., Tessier, B., Lim, K.-H., Gauthereau, I., Choquet, D., Sibarita, J.-B., Park, S., Sainlos, M., Thoumine, O., 2016. Mapping the dynamics and nanoscale organization of synaptic adhesion proteins using monomeric streptavidin. Nat. Commun. 7, 10773. https://doi.org/10.1038/ncomms10773

Chen, J., Yu, S., Fu, Y., Li, X., 2014. Synaptic proteins and receptors defects in autism spectrum disorders. Front. Cell. Neurosci. 8. https://doi.org/10.3389/fncel.2014.00276

Chih, B., Afridi, S.K., Clark, L., Scheiffele, P., 2004. Disorder-associated mutations lead to functional inactivation of neuroligins. Hum. Mol. Genet. 13, 1471-1477. https://doi.org/10.1093/hmg/ddh158

Chih, B., Gollan, L., Scheiffele, P., 2006. Alternative Splicing Controls Selective TransSynaptic Interactions of the Neuroligin-Neurexin Complex. Neuron 51, 171-178. https://doi.org/10.1016/j.neuron.2006.06.005

Choquet, D., Triller, A., 2013. The Dynamic Synapse. Neuron 80, 691-703. https://doi.org/10.1016/j.neuron.2013.10.013

Choy, R.W.-Y., Park, M., Temkin, P., Herring, B.E., Marley, A., Nicoll, R.A., von Zastrow, M., 2014. Retromer Mediates a Discrete Route of Local Membrane Delivery to Dendrites. Neuron 82, 55-62. https://doi.org/10.1016/j.neuron.2014.02.018

Christoforou, A., McGhee, K.A., Morris, S.W., Thomson, P.A., Anderson, S., McLean, A., Torrance, H.S., Le Hellard, S., Pickard, B.S., StClair, D., Muir, W.J., Blackwood, D.H., Porteous, D.J., Evans, K.L., 2011. Convergence of linkage, association and GWAS findings for a candidate region for bipolar disorder and schizophrenia on chromosome 4p. Mol. Psychiatry 16, 240-242. https://doi.org/10.1038/mp.2010.25

Comoletti, D., De Jaco, A., Jennings, L.L., Flynn, R.E., Gaietta, G., Tsigelny, I., Ellisman, M.H., Taylor, P., 2004. The Arg451Cys-Neuroligin-3 Mutation Associated with Autism Reveals a Defect in Protein Processing. J. Neurosci. 24, 4889-4893. https://doi.org/10.1523/JNEUROSCI.0468-04.2004

Craig, A.M., Banker, G., 1994. Neuronal Polarity. Annu. Rev. Neurosci. 17, 267-310. https://doi.org/10.1146/annurev.ne.17.030194.001411

De Jaco, A., Comoletti, D., King, C.C., Taylor, P., 2008. Trafficking of cholinesterases and neuroligins mutant proteins. Chem. Biol. Interact. 175, 349-351. https://doi.org/10.1016/j.cbi.2008.04.023

De Jaco, A., Dubi, N., Comoletti, D., Taylor, P., 2010a. Folding anomalies of neuroligin3 caused by a mutation in the $\alpha / \beta$-hydrolase fold domain. Chem. Biol. Interact. 187, 5658. https://doi.org/10.1016/j.cbi.2010.03.012

De Jaco, A., Lin, M.Z., Dubi, N., Comoletti, D., Miller, M.T., Camp, S., Ellisman, M., Butko, M.T., Tsien, R.Y., Taylor, P., 2010b. Neuroligin Trafficking Deficiencies Arising from Mutations in the $\alpha / \beta$-Hydrolase Fold Protein Family. J. Biol. Chem. 285, 2867428682. https://doi.org/10.1074/jbc.M110.139519

de Wit, J., Ghosh, A., 2015. Specification of synaptic connectivity by cell surface interactions. Nat. Rev. Neurosci. 17, 4-4. https://doi.org/10.1038/nrn.2015.3

de Wit, J., Ghosh, A., 2014. Control of neural circuit formation by leucine-rich repeat proteins. Trends Neurosci. 37, 539-550. https://doi.org/10.1016/j.tins.2014.07.004

de Wit, J., Sylwestrak, E., O'Sullivan, M.L., Otto, S., Tiglio, K., Savas, J.N., Yates, J.R., Comoletti, D., Taylor, P., Ghosh, A., 2009. LRRTM2 Interacts with Neurexin1 and Regulates Excitatory Synapse Formation. Neuron 64, 799-806. https://doi.org/10.1016/j.neuron.2009.12.019

Dean, C., Scholl, F.G., Choih, J., DeMaria, S., Berger, J., Isacoff, E., Scheiffele, P., 2003. Neurexin mediates the assembly of presynaptic terminals. Nat. Neurosci. $6,708-716$. https://doi.org/10.1038/nn1074

Dresbach, T., Neeb, A., Meyer, G., Gundelfinger, E.D., Brose, N., 2004. Synaptic targeting of neuroligin is independent of neurexin and SAP90/PSD95 binding. Mol. Cell. Neurosci. 27, 227-235. https://doi.org/10.1016/j.mcn.2004.06.013

Drissi, R., Dubois, M.-L., Boisvert, F.-M., 2013. Proteomics methods for subcellular proteome analysis. FEBS J. 280, 5626-5634. https://doi.org/10.1111/febs.12502 
Dwyer, N.D., Adler, C.E., Crump, J.G., L'Etoile, N.D., Bargmann, C.I., 2001. Polarized dendritic transport and the AP-1 mu1 clathrin adaptor UNC-101 localize odorant receptors to olfactory cilia. Neuron 31, 277-287.

Ellgaard, L., Helenius, A., 2003. Quality control in the endoplasmic reticulum. Nat. Rev. Mol. Cell Biol. 4, 181-191. https://doi.org/10.1038/nrm1052

Emes, R.D., Grant, S.G.N., 2012. Evolution of Synapse Complexity and Diversity. Annu. Rev. Neurosci. 35, 111-131. https://doi.org/10.1146/annurev-neuro-062111-150433

Fairless, R., Masius, H., Rohlmann, A., Heupel, K., Ahmad, M., Reissner, C., Dresbach, T., Missler, M., 2008. Polarized Targeting of Neurexins to Synapses Is Regulated by their C-Terminal Sequences. J. Neurosci. 28, 12969-12981. https://doi.org/10.1523/JNEUROSCI.5294-07.2008

Farías, G.G., Cuitino, L., Guo, X., Ren, X., Jarnik, M., Mattera, R., Bonifacino, J.S., 2012. Signal-Mediated, AP-1/Clathrin-Dependent Sorting of Transmembrane Receptors to the Somatodendritic Domain of Hippocampal Neurons. Neuron 75, 810-823. https://doi.org/10.1016/j.neuron.2012.07.007

Fu, Y., Huang, Z.J., 2010. Differential dynamics and activity-dependent regulation of - and neurexins at developing GABAergic synapses. Proc. Natl. Acad. Sci. 107, 2269922704. https://doi.org/10.1073/pnas.1011233108

Futai, K., Doty, C.D., Baek, B., Ryu, J., Sheng, M., 2013. Specific Trans-Synaptic Interaction with Inhibitory Interneuronal Neurexin Underlies Differential Ability of Neuroligins to Induce Functional Inhibitory Synapses. J. Neurosci. 33, 3612-3623. https://doi.org/10.1523/JNEUROSCI.1811-12.2013

Gallon, M., Cullen, P.J., 2015. Retromer and sorting nexins in endosomal sorting. Biochem. Soc. Trans. 43, 33-47. https://doi.org/10.1042/BST20140290

Gerrow, K., Romorini, S., Nabi, S.M., Colicos, M.A., Sala, C., El-Husseini, A., 2006. A Preformed Complex of Postsynaptic Proteins Is Involved in Excitatory Synapse Development. Neuron 49, 547-562. https://doi.org/10.1016/j.neuron.2006.01.015

Giagtzoglou, N., Ly, C.V., Bellen, H.J., 2009. Cell Adhesion, the Backbone of the Synapse: "Vertebrate" and "Invertebrate" Perspectives. Cold Spring Harb. Perspect. Biol. 1, a003079-a003079. https://doi.org/10.1101/cshperspect.a003079

Giannone, G., Mondin, M., Grillo-Bosch, D., Tessier, B., Saint-Michel, E., Czöndör, K., Sainlos, M., Choquet, D., Thoumine, O., 2013. Neurexin-1 $\beta$ Binding to Neuroligin-1 Triggers the Preferential Recruitment of PSD-95 versus Gephyrin through Tyrosine Phosphorylation of Neuroligin-1. Cell Rep. 3, 1996-2007. https://doi.org/10.1016/j.celrep.2013.05.013

Gokce, O., Sudhof, T.C., 2013. Membrane-Tethered Monomeric Neurexin LNS-Domain Triggers Synapse Formation. J. Neurosci. 33, 14617-14628. https://doi.org/10.1523/JNEUROSCI.1232-13.2013

Graf, E.R., Zhang, X., Jin, S.-X., Linhoff, M.W., Craig, A.M., 2004. Neurexins Induce Differentiation of GABA and Glutamate Postsynaptic Specializations via Neuroligins. Cell 119, 1013-1026. https://doi.org/10.1016/j.cell.2004.11.035

Grupe, A., Li, Y., Rowland, C., Nowotny, P., Hinrichs, A.L., Smemo, S., Kauwe, J.S.K., Maxwell, T.J., Cherny, S., Doil, L., Tacey, K., van Luchene, R., Myers, A., WavrantDe Vrièze, F., Kaleem, M., Hollingworth, P., Jehu, L., Foy, C., Archer, N., Hamilton, G., Holmans, P., Morris, C.M., Catanese, J., Sninsky, J., White, T.J., Powell, J., Hardy, J., O'Donovan, M., Lovestone, S., Jones, L., Morris, J.C., Thal, L., Owen, M., Williams, J., Goate, A., 2006. A Scan of Chromosome 10 Identifies a Novel Locus Showing Strong Association with Late-Onset Alzheimer Disease. Am. J. Hum. Genet. 78, 78-88. https://doi.org/10.1086/498851

Guo, Y., Sirkis, D.W., Schekman, R., 2014. Protein Sorting at the trans -Golgi Network. Annu. Rev. Cell Dev. Biol. 30, 169-206. https://doi.org/10.1146/annurev-cellbio100913-013012

Gutiérrez, R.C., Flynn, R., Hung, J., Kertesz, A.C., Sullivan, A., Zamponi, G.W., El-Husseini, A., Colicos, M.A., 2009. Activity-driven mobilization of post-synaptic proteins. Eur. J. Neurosci. 30, 2042-2052. https://doi.org/10.1111/j.1460-9568.2009.07007.x 
Harris, K.P., Zhang, Y.V., Piccioli, Z.D., Perrimon, N., Littleton, J.T., 2016. The postsynaptic t-SNARE Syntaxin 4 controls traffic of Neuroligin 1 and Synaptotagmin 4 to regulate retrograde signaling. eLife 5. https://doi.org/10.7554/eLife.13881

Harterink, M., Port, F., Lorenowicz, M.J., McGough, I.J., Silhankova, M., Betist, M.C., van Weering, J.R.T., van Heesbeen, R.G.H.P., Middelkoop, T.C., Basler, K., Cullen, P.J., Korswagen, H.C., 2011. A SNX3-dependent retromer pathway mediates retrograde transport of the Wnt sorting receptor Wntless and is required for Wnt secretion. Nat. Cell Biol. 13, 914-923. https://doi.org/10.1038/ncb2281

Heidenreich, M., Zhang, F., 2016. Applications of CRISPR-Cas systems in neuroscience. Nat. Rev. Neurosci. 17, 36-44. https://doi.org/10.1038/nrn.2015.2

Heisler, F.F., Lee, H.K., Gromova, K.V., Pechmann, Y., Schurek, B., Ruschkies, L., Schroeder, M., Schweizer, M., Kneussel, M., 2014. GRIP1 interlinks N-cadherin and AMPA receptors at vesicles to promote combined cargo transport into dendrites. Proc. Natl. Acad. Sci. 111, 5030-5035. https://doi.org/10.1073/pnas.1304301111

Hetz, C., Chevet, E., Oakes, S.A., 2015. Proteostasis control by the unfolded protein response. Nat. Cell Biol. 17, 829-838. https://doi.org/10.1038/ncb3184

Hirokawa, N., Noda, Y., Tanaka, Y., Niwa, S., 2009. Kinesin superfamily motor proteins and intracellular transport. Nat. Rev. Mol. Cell Biol. 10, 682-696. https://doi.org/10.1038/nrm2774

Hoogenraad, C.C., Milstein, A.D., Ethell, I.M., Henkemeyer, M., Sheng, M., 2005. GRIP1 controls dendrite morphogenesis by regulating EphB receptor trafficking. Nat. Neurosci. 8, 906-915. https://doi.org/10.1038/nn1487

Hoon, M., Soykan, T., Falkenburger, B., Hammer, M., Patrizi, A., Schmidt, K.-F., SassoePognetto, M., Lowel, S., Moser, T., Taschenberger, H., Brose, N., Varoqueaux, F., 2011. Neuroligin-4 is localized to glycinergic postsynapses and regulates inhibition in the retina. Proc. Natl. Acad. Sci. 108, 3053-3058. https://doi.org/10.1073/pnas.1006946108

Horton, A.C., Ehlers, M.D., 2004. Secretory trafficking in neuronal dendrites. Nat. Cell Biol. 6, 585-591. https://doi.org/10.1038/ncb0704-585

Hsu, V.W., Bai, M., Li, J., 2012. Getting active: protein sorting in endocytic recycling. Nat. Rev. Mol. Cell Biol. https://doi.org/10.1038/nrm3332

Huber, K.M., Roder, J.C., Bear, M.F., 2001. Chemical Induction of mGluR5- and Protein Synthesis-Dependent Long-Term Depression in Hippocampal Area CA1. J. Neurophysiol. 86, 321-325. https://doi.org/10.1152/jn.2001.86.1.321

Hussain, N.K., Diering, G.H., Sole, J., Anggono, V., Huganir, R.L., 2014. Sorting Nexin 27 regulates basal and activity-dependent trafficking of AMPARs. Proc. Natl. Acad. Sci. 111, 11840-11845. https://doi.org/10.1073/pnas.1412415111

lida, J., Hirabayashi, S., Sato, Y., Hata, Y., 2004. Synaptic scaffolding molecule is involved in the synaptic clustering of neuroligin. Mol. Cell. Neurosci. 27, 497-508. https://doi.org/10.1016/j.mcn.2004.08.006

Jacob, T.C., Moss, S.J., Jurd, R., 2008. GABAA receptor trafficking and its role in the dynamic modulation of neuronal inhibition. Nat. Rev. Neurosci. 9, 331-343. https://doi.org/10.1038/nrn2370

Jahn, R., Lang, T., Südhof, T.C., 2003. Membrane Fusion. Cell 112, 519-533. https://doi.org/10.1016/S0092-8674(03)00112-0

Jahn, R., Scheller, R.H., 2006. SNAREs--engines for membrane fusion. Nat. Rev. Mol. Cell Biol. 7, 631-643. https://doi.org/10.1038/nrm2002

Jain, S., Farias, G.G., Bonifacino, J.S., 2015. Polarized sorting of the copper transporter ATP7B in neurons mediated by recognition of a dileucine signal by AP-1. Mol. Biol. Cell 26, 218-228. https://doi.org/10.1091/mbc.E14-07-1177

Jamain, S., Quach, H., Betancur, C., Råstam, M., Colineaux, C., Gillberg, I.C., Soderstrom, H., Giros, B., Leboyer, M., Gillberg, C., Bourgeron, T., Gillberg, C., Råstam, M., Gillberg, C., Nydén, A., Söderström, H., Leboyer, M., Betancur, C., Philippe, A., Giros, B., Colineaux, C., Cohen, D., Chabane, N., Mouren-Siméoni, M.-C., Brice, A., Sponheim, E., Spurkland, I., Skjeldal, O.H., Coleman, M., Pearl, P.L., Cohen, I.L., 
Tsiouris, J., Zappella, M., Menchetti, G., Pompella, A., Aschauer, H., Van Maldergem, L., 2003. Mutations of the X-linked genes encoding neuroligins NLGN3 and NLGN4 are associated with autism. Nat. Genet. 34, 27-29. https://doi.org/10.1038/ng1136

Jang, S., Lee, H., Kim, E., 2017. Synaptic adhesion molecules and excitatory synaptic transmission. Curr. Opin. Neurobiol. 45, 45-50. https://doi.org/10.1016/j.conb.2017.03.005

Jeyifous, O., Waites, C.L., Specht, C.G., Fujisawa, S., Schubert, M., Lin, E.I., Marshall, J., Aoki, C., de Silva, T., Montgomery, J.M., Garner, C.C., Green, W.N., 2009. SAP97 and CASK mediate sorting of NMDA receptors through a previously unknown secretory pathway. Nat. Neurosci. 12, 1011-1019. https://doi.org/10.1038/nn.2362

Jurado, S., Goswami, D., Zhang, Y., Molina, A.J.M., Südhof, T.C., Malenka, R.C., 2013. LTP Requires a Unique Postsynaptic SNARE Fusion Machinery. Neuron 77, 542-558. https://doi.org/10.1016/j.neuron.2012.11.029

Kang, H., Han, K.A., Won, S.Y., Kim, H.M., Lee, Y.-H., Ko, J., Um, J.W., 2016. Slitrk Missense Mutations Associated with Neuropsychiatric Disorders Distinctively Impair Slitrk Trafficking and Synapse Formation. Front. Mol. Neurosci. 9. https://doi.org/10.3389/fnmol.2016.00104

Kang, Y., Ge, Y., Cassidy, R.M., Lam, V., Luo, L., Moon, K.-M., Lewis, R., Molday, R.S., Wong, R.O.L., Foster, L.J., Craig, A.M., 2014. A Combined Transgenic Proteomic Analysis and Regulated Trafficking of Neuroligin-2. J. Biol. Chem. 289, 29350-29364. https://doi.org/10.1074/jbc.M114.549279

Kang, Y., Zhang, X., Dobie, F., Wu, H., Craig, A.M., 2008. Induction of GABAergic Postsynaptic Differentiation by a-Neurexins. J. Biol. Chem. 283, 2323-2334. https://doi.org/10.1074/jbc.M703957200

Kennedy, M.J., Davison, I.G., Robinson, C.G., Ehlers, M.D., 2010. Syntaxin-4 Defines a Domain for Activity-Dependent Exocytosis in Dendritic Spines. Cell 141, 524-535. https://doi.org/10.1016/j.cell.2010.02.042

Kim, J., Zhao, T., Petralia, R.S., Yu, Y., Peng, H., Myers, E., Magee, J.C., 2011. mGRASP enables mapping mammalian synaptic connectivity with light microscopy. Nat. Methods 9, 96-102. https://doi.org/10.1038/nmeth.1784

Ko, J., Fuccillo, M.V., Malenka, R.C., Südhof, T.C., 2009a. LRRTM2 Functions as a Neurexin Ligand in Promoting Excitatory Synapse Formation. Neuron 64, 791-798. https://doi.org/10.1016/j.neuron.2009.12.012

Ko, J., Zhang, C., Arac, D., Boucard, A.A., Brunger, A.T., Südhof, T.C., 2009b. Neuroligin-1 performs neurexin-dependent and neurexin-independent functions in synapse validation. EMBO J. 28, 3244-3255. https://doi.org/10.1038/emboj.2009.249

LaMonte, B.H., Wallace, K.E., Holloway, B.A., Shelly, S.S., Ascaño, J., Tokito, M., Van Winkle, T., Howland, D.S., Holzbaur, E.L.F., 2002. Disruption of dynein/dynactin inhibits axonal transport in motor neurons causing late-onset progressive degeneration. Neuron 34, 715-727.

Lane, R.F., Raines, S.M., Steele, J.W., Ehrlich, M.E., Lah, J.A., Small, S.A., Tanzi, R.E., Attie, A.D., Gandy, S., 2010. Diabetes-Associated SorCS1 Regulates Alzheimer's Amyloid- Metabolism: Evidence for Involvement of SorL1 and the Retromer Complex. J. Neurosci. 30, 13110-13115. https://doi.org/10.1523/JNEUROSCI.3872-10.2010

Lane, R.F., Steele, J.W., Cai, D., Ehrlich, M.E., Attie, A.D., Gandy, S., 2013. Protein Sorting Motifs in the Cytoplasmic Tail of SorCS1 Control Generation of Alzheimer's AmyloidPeptide. J. Neurosci. 33, 7099-7107. https://doi.org/10.1523/JNEUROSCI.527012.2013

Lauffer, B.E.L., Melero, C., Temkin, P., Lei, C., Hong, W., Kortemme, T., von Zastrow, M., 2010. SNX27 mediates PDZ-directed sorting from endosomes to the plasma membrane. J. Cell Biol. 190, 565-574. https://doi.org/10.1083/jcb.201004060

Laumet, G., Chouraki, V., Grenier-Boley, B., Legry, V., Heath, S., Zelenika, D., Fievet, N., Hannequin, D., Delepine, M., Pasquier, F., Hanon, O., Brice, A., Epelbaum, J., Berr, C., Dartigues, J.-F., Tzourio, C., Campion, D., Lathrop, M., Bertram, L., Amouyel, P., Lambert, J.-C., 2010. Systematic Analysis of Candidate Genes for Alzheimer's 
Disease in a French, Genome-Wide Association Study. J. Alzheimers Dis. 20, 11811188. https://doi.org/10.3233/JAD-2010-100126

Laurén, J., Airaksinen, M.S., Saarma, M., Timmusk, T., 2003. A novel gene family encoding leucine-rich repeat transmembrane proteins differentially expressed in the nervous system. Genomics 81, 411-421.

Levinson, J.N., Chéry, N., Huang, K., Wong, T.P., Gerrow, K., Kang, R., Prange, O., Wang, Y.T., El-Husseini, A., 2005. Neuroligins Mediate Excitatory and Inhibitory Synapse Formation: INVOLVEMENT OF PSD-95 AND NEUREXIN-1 $\beta$ IN NEUROLIGININDUCED SYNAPTIC SPECIFICITY. J. Biol. Chem. 280, 17312-17319. https://doi.org/10.1074/jbc.M413812200

Levinson, J.N., Li, R., Kang, R., Moukhles, H., El-Husseini, A., Bamji, S.X., 2010. Postsynaptic scaffolding molecules modulate the localization of neuroligins. Neuroscience 165, 782-793. https://doi.org/10.1016/j.neuroscience.2009.11.016

Li, H., Wetten, S., Li, L., St. Jean, P.L., Upmanyu, R., Surh, L., Hosford, D., Barnes, M.R., Briley, J.D., Borrie, M., Coletta, N., Delisle, R., Dhalla, D., Ehm, M.G., Feldman, H.H., Fornazzari, L., Gauthier, S., Goodgame, N., Guzman, D., Hammond, S., Hollingworth, P., Hsiung, G.-Y., Johnson, J., Kelly, D.D., Keren, R., Kertesz, A., King, K.S., Lovestone, S., Loy-English, I., Matthews, P.M., Owen, M.J., Plumpton, M., PrysePhillips, W., Prinjha, R.K., Richardson, J.C., Saunders, A., Slater, A.J., St. GeorgeHyslop, P.H., Stinnett, S.W., Swartz, J.E., Taylor, R.L., Wherrett, J., Williams, J., Yarnall, D.P., Gibson, R.A., Irizarry, M.C., Middleton, L.T., Roses, A.D., 2008. Candidate Single-Nucleotide Polymorphisms From a Genomewide Association Study of Alzheimer Disease. Arch. Neurol. 65. https://doi.org/10.1001/archneurol.2007.3

Li, P., Merrill, S.A., Jorgensen, E.M., Shen, K., 2016. Two Clathrin Adaptor Protein Complexes Instruct Axon-Dendrite Polarity. Neuron 90, 564-580. https://doi.org/10.1016/j.neuron.2016.04.020

Liang, X., Slifer, M., Martin, E.R., Schnetz-Boutaud, N., Bartlett, J., Anderson, B., Züchner, S., Gwirtsman, H., Gilbert, J.R., Pericak-Vance, M.A., Haines, J.L., 2009. Genomic convergence to identify candidate genes for Alzheimer Disease on chromosome 10. Hum. Mutat. 30, 463-471. https://doi.org/10.1002/humu.20953

Lin, Y.-C., Frei, J.A., Kilander, M.B.C., Shen, W., Blatt, G.J., 2016. A Subset of AutismAssociated Genes Regulate the Structural Stability of Neurons. Front. Cell. Neurosci. 10. https://doi.org/10.3389/fncel.2016.00263

Linhoff, M.W., Laurén, J., Cassidy, R.M., Dobie, F.A., Takahashi, H., Nygaard, H.B., Airaksinen, M.S., Strittmatter, S.M., Craig, A.M., 2009. An Unbiased Expression Screen for Synaptogenic Proteins Identifies the LRRTM Protein Family as Synaptic Organizers. Neuron 61, 734-749. https://doi.org/10.1016/j.neuron.2009.01.017

Lionel, A.C., Crosbie, J., Barbosa, N., Goodale, T., Thiruvahindrapuram, B., Rickaby, J., Gazzellone, M., Carson, A.R., Howe, J.L., Wang, Z., Wei, J., Stewart, A.F.R., Roberts, R., McPherson, R., Fiebig, A., Franke, A., Schreiber, S., Zwaigenbaum, L., Fernandez, B.A., Roberts, W., Arnold, P.D., Szatmari, P., Marshall, C.R., Schachar, R., Scherer, S.W., 2011. Rare Copy Number Variation Discovery and Cross-Disorder Comparisons Identify Risk Genes for ADHD. Sci. Transl. Med. 3, 95ra75-95ra75. https://doi.org/10.1126/scitranslmed.3002464

Loh, K.H., Stawski, P.S., Draycott, A.S., Udeshi, N.D., Lehrman, E.K., Wilton, D.K., Svinkina, T., Deerinck, T.J., Ellisman, M.H., Stevens, B., Carr, S.A., Ting, A.Y., 2016. Proteomic Analysis of Unbounded Cellular Compartments: Synaptic Clefts. Cell 166, 1295-1307.e21. https://doi.org/10.1016/j.cell.2016.07.041

Loo, L.S., Tang, N., Al-Haddawi, M., Stewart Dawe, G., Hong, W., 2014. A role for sorting nexin 27 in AMPA receptor trafficking. Nat. Commun. 5. https://doi.org/10.1038/ncomms4176

Low, S.H., Chapin, S.J., Weimbs, T., Kömüves, L.G., Bennett, M.K., Mostov, K.E., 1996. Differential localization of syntaxin isoforms in polarized Madin-Darby canine kidney cells. Mol. Biol. Cell 7, 2007-2018. 
Low, S.H., Chapin, S.J., Wimmer, C., Whiteheart, S.W., Kömüves, L.G., Mostov, K.E., Weimbs, T., 1998. The SNARE machinery is involved in apical plasma membrane trafficking in MDCK cells. J. Cell Biol. 141, 1503-1513.

Low, S.H., Marmorstein, L.Y., Miura, M., Li, X., Kudo, N., Marmorstein, A.D., Weimbs, T., 2002. Retinal pigment epithelial cells exhibit unique expression and localization of plasma membrane syntaxins which may contribute to their trafficking phenotype. J. Cell Sci. 115, 4545-4553.

Margeta, M.A., Wang, G.J., Shen, K., 2009. Clathrin adaptor AP-1 complex excludes multiple postsynaptic receptors from axons in C. elegans. Proc. Natl. Acad. Sci. 106, 16321637. https://doi.org/10.1073/pnas.0812078106

Martens, S., McMahon, H.T., 2008. Mechanisms of membrane fusion: disparate players and common principles. Nat. Rev. Mol. Cell Biol. 9, 543-556. https://doi.org/10.1038/nrm2417

McNally, K.E., Faulkner, R., Steinberg, F., Gallon, M., Ghai, R., Pim, D., Langton, P., Pearson, N., Danson, C.M., Nägele, H., Morris, L.L., Singla, A., Overlee, B.L., Heesom, K.J., Sessions, R., Banks, L., Collins, B.M., Berger, I., Billadeau, D.D., Burstein, E., Cullen, P.J., 2017. Retriever is a multiprotein complex for retromerindependent endosomal cargo recycling. Nat. Cell Biol. 19, 1214-1225. https://doi.org/10.1038/ncb3610

Mikhaylova, M., Bera, S., Kobler, O., Frischknecht, R., Kreutz, M.R., 2016. A Dendritic Golgi Satellite between ERGIC and Retromer. Cell Rep. 14, 189-199. https://doi.org/10.1016/j.celrep.2015.12.024

Minatohara, K., Murata, Y., Fujiyoshi, Y., Doi, T., 2015. An intracellular domain with a novel sequence regulates cell surface expression and synaptic clustering of leucine-rich repeat transmembrane proteins in hippocampal neurons. J. Neurochem. 134, 618628. https://doi.org/10.1111/jnc.13159

Mondal, P., Khamo, J.S., Krishnamurthy, V.V., Cai, Q., Zhang, K., 2017. Drive the Car(go)s-New Modalities to Control Cargo Trafficking in Live Cells. Front. Mol. Neurosci. 10. https://doi.org/10.3389/fnmol.2017.00004

Nakanishi, M., Nomura, J., Ji, X., Tamada, K., Arai, T., Takahashi, E., Bućan, M., Takumi, T., 2017. Functional significance of rare neuroligin 1 variants found in autism. PLOS Genet. 13, e1006940. https://doi.org/10.1371/journal.pgen.1006940

Nakatsu, F., Okada, M., Mori, F., Kumazawa, N., Iwasa, H., Zhu, G., Kasagi, Y., Kamiya, H., Harada, A., Nishimura, K., Takeuchi, A., Miyazaki, T., Watanabe, M., Yuasa, S., Manabe, T., Wakabayashi, K., Kaneko, S., Saito, T., Ohno, H., 2004. Defective function of GABA-containing synaptic vesicles in mice lacking the AP-3B clathrin adaptor. J. Cell Biol. 167, 293-302. https://doi.org/10.1083/jcb.200405032

Neupert, C., Schneider, R., Klatt, O., Reissner, C., Repetto, D., Biermann, B., Niesmann, K., Missler, M., Heine, M., 2015. Regulated Dynamic Trafficking of Neurexins Inside and Outside of Synaptic Terminals. J. Neurosci. 35, 13629-13647. https://doi.org/10.1523/JNEUROSCI.4041-14.2015

Newell-Litwa, K., Salazar, G., Smith, Y., Faundez, V., 2009. Roles of BLOC-1 and Adaptor Protein-3 Complexes in Cargo Sorting to Synaptic Vesicles. Mol. Biol. Cell 20, 14411453. https://doi.org/10.1091/mbc.E08-05-0456

Ollila, H.M., Soronen, P., Silander, K., Palo, O.M., Kieseppä, T., Kaunisto, M.A., Lönnqvist, J., Peltonen, L., Partonen, T., Paunio, T., 2009. Findings from bipolar disorder genome-wide association studies replicate in a Finnish bipolar family-cohort. Mol. Psychiatry 14, 351-353. https://doi.org/10.1038/mp.2008.122

Palmer, M.J., Irving, A.J., Seabrook, G.R., Jane, D.E., Collingridge, G.L., 1997. The group I mGlu receptor agonist DHPG induces a novel form of LTD in the CA1 region of the hippocampus. Neuropharmacology 36, 1517-1532.

Peixoto, R.T., Kunz, P.A., Kwon, H., Mabb, A.M., Sabatini, B.L., Philpot, B.D., Ehlers, M.D., 2012. Transsynaptic Signaling by Activity-Dependent Cleavage of Neuroligin-1. Neuron 76, 396-409. https://doi.org/10.1016/j.neuron.2012.07.006 
Perez de Arce, K., Schrod, N., Metzbower, S.W.R., Allgeyer, E., Kong, G.K.-W., Tang, A.-H., Krupp, A.J., Stein, V., Liu, X., Bewersdorf, J., Blanpied, T.A., Lucić, V., Biederer, T., 2015. Topographic Mapping of the Synaptic Cleft into Adhesive Nanodomains. Neuron 88, 1165-1172. https://doi.org/10.1016/j.neuron.2015.11.011

Poulopoulos, A., Soykan, T., Tuffy, L.P., Hammer, M., Varoqueaux, F., Brose, N., 2012. Homodimerization and isoform-specific heterodimerization of neuroligins. Biochem. J. 446, 321-330. https://doi.org/10.1042/BJ20120808

Prange, O., Wong, T.P., Gerrow, K., Wang, Y.T., El-Husseini, A., 2004. A balance between excitatory and inhibitory synapses is controlled by PSD-95 and neuroligin. Proc. Natl. Acad. Sci. 101, 13915-13920. https://doi.org/10.1073/pnas.0405939101

Rabaneda, L.G., Robles-Lanuza, E., Nieto-González, J.L., Scholl, F.G., 2014. Neurexin Dysfunction in Adult Neurons Results in Autistic-like Behavior in Mice. Cell Rep. 8, 338-346. https://doi.org/10.1016/j.celrep.2014.06.022

Reales, E., Sharma, N., Low, S.H., Fölsch, H., Weimbs, T., 2011. Basolateral sorting of syntaxin 4 is dependent on its $\mathrm{N}$-terminal domain and the AP1B clathrin adaptor, and required for the epithelial cell polarity. PloS One 6, e21181. https://doi.org/10.1371/journal.pone.0021181

Reitz, C., Tokuhiro, S., Clark, L.N., Conrad, C., Vonsattel, J.-P., Hazrati, L.-N., Palotás, A., Lantigua, R., Medrano, M., Z. Jiménez -Velázquez, I., Vardarajan, B., Simkin, I., Haines, J.L., Pericak -Vance, M.A., Farrer, L.A., Lee, J.H., Rogaeva, E., GeorgeHyslop, P.S., Mayeux, R., 2011. SORCS1 alters amyloid precursor protein processing and variants may increase Alzheimer's disease risk. Ann. Neurol. 69, 47-64. https://doi.org/10.1002/ana.22308

Rizo, J., Rosenmund, C., 2008. Synaptic vesicle fusion. Nat. Struct. Mol. Biol. 15, 665-674.

Rizo, J., Südhof, T.C., 2012. The membrane fusion enigma: SNAREs, Sec1/Munc18 proteins, and their accomplices--guilty as charged? Annu. Rev. Cell Dev. Biol. 28, 279-308. https://doi.org/10.1146/annurev-cellbio-101011-155818

Rosales, C.R., Osborne, K.D., Zuccarino, G.V., Scheiffele, P., Silverman, M.A., 2005. A cytoplasmic motif targets neuroligin-1 exclusively to dendrites of cultured hippocampal neurons. Eur. J. Neurosci. 22, 2381-2386. https://doi.org/10.1111/j.1460-9568.2005.04400.x

Salazar, G., 2003. The Zinc Transporter ZnT3 Interacts with AP-3 and It Is Preferentially Targeted to a Distinct Synaptic Vesicle Subpopulation. Mol. Biol. Cell 15, 575-587. https://doi.org/10.1091/mbc.E03-06-0401

Salazar, G., Love, R., Styers, M.L., Werner, E., Peden, A., Rodriguez, S., Gearing, M., Wainer, B.H., Faundez, V., 2004. AP-3-dependent Mechanisms Control the Targeting of a Chloride Channel (CIC-3) in Neuronal and Non-neuronal Cells. J. Biol. Chem. 279, 25430-25439. https://doi.org/10.1074/jbc.M402331200

Sanders, S.J., Murtha, M.T., Gupta, A.R., Murdoch, J.D., Raubeson, M.J., Willsey, A.J., Ercan-Sencicek, A.G., DiLullo, N.M., Parikshak, N.N., Stein, J.L., Walker, M.F., Ober, G.T., Teran, N.A., Song, Y., El-Fishawy, P., Murtha, R.C., Choi, M., Overton, J.D., Bjornson, R.D., Carriero, N.J., Meyer, K.A., Bilguvar, K., Mane, S.M., Šestan, N., Lifton, R.P., Günel, M., Roeder, K., Geschwind, D.H., Devlin, B., State, M.W., 2012. De novo mutations revealed by whole-exome sequencing are strongly associated with autism. Nature 485, 237-241. https://doi.org/10.1038/nature10945

Saura, C.A., Servián-Morilla, E., Scholl, F.G., 2011. Presenilin/Y-Secretase Regulates Neurexin Processing at Synapses. PLoS ONE 6, e19430. https://doi.org/10.1371/journal.pone.0019430

Savas, J.N., Ribeiro, L.F., Wierda, K.D., Wright, R., DeNardo-Wilke, L.A., Rice, H.C., Chamma, I., Wang, Y.-Z., Zemla, R., Lavallée-Adam, M., Vennekens, K.M., O'Sullivan, M.L., Antonios, J.K., Hall, E.A., Thoumine, O., Attie, A.D., Yates, J.R., Ghosh, A., de Wit, J., 2015. The Sorting Receptor SorCS1 Regulates Trafficking of Neurexin and AMPA Receptors. Neuron 87, 764-780.

https://doi.org/10.1016/j.neuron.2015.08.007 
Schapitz, I.U., Behrend, B., Pechmann, Y., Lappe-Siefke, C., Kneussel, S.J., Wallace, K.E., Stempel, A.V., Buck, F., Grant, S.G.N., Schweizer, M., Schmitz, D., Schwarz, J.R., Holzbaur, E.L.F., Kneussel, M., 2010. Neuroligin 1 Is Dynamically Exchanged at Postsynaptic Sites. J. Neurosci. 30, 12733-12744. https://doi.org/10.1523/JNEUROSCI.0896-10.2010

Seaman, M.N.J., 2012. The retromer complex - endosomal protein recycling and beyond. J. Cell Sci. 125, 4693-4702. https://doi.org/10.1242/jcs.103440

Seaman, M.N.J., Michael McCaffery, J., Emr, S.D., 1998. A Membrane Coat Complex Essential for Endosome-to-Golgi Retrograde Transport in Yeast. J. Cell Biol. 142, 665-681. https://doi.org/10.1083/jcb.142.3.665

Setou, M., Nakagawa, T., Seog, D.-H., Hirokawa, N., 2000. Kinesin Superfamily Motor Protein KIF17 and mLin-10 in NMDA Receptor-Containing Vesicle Transport. Science 288, 1796-1802. https://doi.org/10.1126/science.288.5472.1796

Setou, M., Seog, D.-H., Tanaka, Y., Kanai, Y., Takei, Y., Kawagishi, M., Hirokawa, N., 2002. Glutamate-receptor-interacting protein GRIP1 directly steers kinesin to dendrites. Nature 417, 83-87. https://doi.org/10.1038/nature743

Sharma, N., Low, S.H., Misra, S., Pallavi, B., Weimbs, T., 2006. Apical targeting of syntaxin 3 is essential for epithelial cell polarity. J. Cell Biol. 173, 937-948. https://doi.org/10.1083/jcb.200603132

Shipman, S.L., Nicoll, R.A., 2012. Dimerization of postsynaptic neuroligin drives synaptic assembly via transsynaptic clustering of neurexin. Proc. Natl. Acad. Sci. 109, 1943219437. https://doi.org/10.1073/pnas.1217633109

Shipman, S.L., Schnell, E., Hirai, T., Chen, B.-S., Roche, K.W., Nicoll, R.A., 2011. Functional dependence of neuroligin on a new non-PDZ intracellular domain. Nat. Neurosci. 14, 718-726. https://doi.org/10.1038/nn.2825

Siddiqui, T.J., Craig, A.M., 2011. Synaptic organizing complexes. Curr. Opin. Neurobiol. 21, 132-143. https://doi.org/10.1016/j.conb.2010.08.016

Siddiqui, T.J., Pancaroglu, R., Kang, Y., Rooyakkers, A., Craig, A.M., 2010. LRRTMs and Neuroligins Bind Neurexins with a Differential Code to Cooperate in Glutamate Synapse Development. J. Neurosci. 30, 7495-7506. https://doi.org/10.1523/JNEUROSCI.0470-10.2010

Small, S.A., Petsko, G.A., 2015. Retromer in Alzheimer disease, Parkinson disease and other neurological disorders. Nat. Rev. Neurosci. 16, 126-132. https://doi.org/10.1038/nrn3896

Song, J.-Y., Ichtchenko, K., Sudhof, T.C., Brose, N., 1999. Neuroligin 1 is a postsynaptic celladhesion molecule of excitatory synapses. Proc. Natl. Acad. Sci. 96, 1100-1105. https://doi.org/10.1073/pnas.96.3.1100

Soo Hoo, L., Banna, C.D., Radeke, C.M., Sharma, N., Albertolle, M.E., Low, S.H., Weimbs, T., Vandenberg, C.A., 2016. The SNARE Protein Syntaxin 3 Confers Specificity for Polarized Axonal Trafficking in Neurons. PLOS ONE 11, e0163671. https://doi.org/10.1371/journal.pone.0163671

Stachniak, T.J., Ghosh, A., Sternson, S.M., 2014. Chemogenetic Synaptic Silencing of Neural Circuits Localizes a Hypothalamus $\rightarrow$ Midbrain Pathway for Feeding Behavior. Neuron 82, 797-808. https://doi.org/10.1016/j.neuron.2014.04.008

Standley, S., Roche, K.W., McCallum, J., Sans, N., Wenthold, R.J., 2000. PDZ domain suppression of an ER retention signal in NMDA receptor NR1 splice variants. Neuron 28, 887-898.

Steinberg, F., Gallon, M., Winfield, M., Thomas, E.C., Bell, A.J., Heesom, K.J., Tavaré, J.M., Cullen, P.J., 2013. A global analysis of SNX27-retromer assembly and cargo specificity reveals a function in glucose and metal ion transport. Nat. Cell Biol. 15, 461-471. https://doi.org/10.1038/ncb2721

Südhof, T.C., 2017. Synaptic Neurexin Complexes: A Molecular Code for the Logic of Neural Circuits. Cell 171, 745-769. https://doi.org/10.1016/j.cell.2017.10.024

Südhof, T.C., 2008. Neuroligins and neurexins link synaptic function to cognitive disease. Nature 455, 903-911. https://doi.org/10.1038/nature07456 
Südhof, T.C., 2004. THE SYNAPTIC VESICLE CYCLE. Annu. Rev. Neurosci. 27, 509-547. https://doi.org/10.1146/annurev.neuro.26.041002.131412

Sudhof, T.C., Rothman, J.E., 2009. Membrane Fusion: Grappling with SNARE and SM Proteins. Science 323, 474-477. https://doi.org/10.1126/science.1161748

Suzuki, K., Hayashi, Y., Nakahara, S., Kumazaki, H., Prox, J., Horiuchi, K., Zeng, M., Tanimura, S., Nishiyama, Y., Osawa, S., Sehara-Fujisawa, A., Saftig, P., Yokoshima, S., Fukuyama, T., Matsuki, N., Koyama, R., Tomita, T., Iwatsubo, T., 2012. ActivityDependent Proteolytic Cleavage of Neuroligin-1. Neuron 76, 410-422. https://doi.org/10.1016/j.neuron.2012.10.003

Tabuchi, K., Blundell, J., Etherton, M.R., Hammer, R.E., Liu, X., Powell, C.M., Sudhof, T.C., 2007. A Neuroligin-3 Mutation Implicated in Autism Increases Inhibitory Synaptic Transmission in Mice. Science 318, 71-76. https://doi.org/10.1126/science.1146221

Takahashi, H., Craig, A.M., 2013. Protein tyrosine phosphatases PTPס, PTP $\sigma$, and LAR: presynaptic hubs for synapse organization. Trends Neurosci. 36, 522-534. https://doi.org/10.1016/j.tins.2013.06.002

Temkin, P., Lauffer, B., Jäger, S., Cimermancic, P., Krogan, N.J., von Zastrow, M., 2011. SNX27 mediates retromer tubule entry and endosome-to-plasma membrane trafficking of signalling receptors. Nat. Cell Biol. 13, 717-723. https://doi.org/10.1038/ncb2252

ter Beest, M.B.A., Chapin, S.J., Avrahami, D., Mostov, K.E., 2005. The role of syntaxins in the specificity of vesicle targeting in polarized epithelial cells. Mol. Biol. Cell 16, 57845792. https://doi.org/10.1091/mbc.E05-07-0661

Terauchi, A., Timmons, K.M., Kikuma, K., Pechmann, Y., Kneussel, M., Umemori, H., 2015. Selective synaptic targeting of the excitatory and inhibitory presynaptic organizers FGF22 and FGF7. J. Cell Sci. 128, 281-292. https://doi.org/10.1242/jcs.158337

Terenzio, M., Schiavo, G., Fainzilber, M., 2017. Compartmentalized Signaling in Neurons: From Cell Biology to Neuroscience. Neuron 96, 667-679. https://doi.org/10.1016/j.neuron.2017.10.015

Tharkeshwar, A.K., Trekker, J., Vermeire, W., Pauwels, J., Sannerud, R., Priestman, D.A., te Vruchte, D., Vints, K., Baatsen, P., Decuypere, J.-P., Lu, H., Martin, S., Vangheluwe, P., Swinnen, J.V., Lagae, L., Impens, F., Platt, F.M., Gevaert, K., Annaert, W., 2017. A novel approach to analyze lysosomal dysfunctions through subcellular proteomics and lipidomics: the case of NPC1 deficiency. Sci. Rep. 7, 41408. https://doi.org/10.1038/srep41408

Tong, X.-J., López-Soto, E.J., Li, L., Liu, H., Nedelcu, D., Lipscombe, D., Hu, Z., Kaplan, J.M., 2017. Retrograde Synaptic Inhibition Is Mediated by a-Neurexin Binding to the a2ठ Subunits of N-Type Calcium Channels. Neuron 95, 326-340.e5. https://doi.org/10.1016/j.neuron.2017.06.018

Torres, R., Firestein, B.L., Dong, H., Staudinger, J., Olson, E.N., Huganir, R.L., Bredt, D.S., Gale, N.W., Yancopoulos, G.D., 1998. PDZ proteins bind, cluster, and synaptically colocalize with Eph receptors and their ephrin ligands. Neuron 21, 1453-1463.

Tu, R., Qian, J., Rui, M., Tao, N., Sun, M., Zhuang, Y., Lv, H., Han, J., Li, M., Xie, W., 2017. Proteolytic cleavage is required for functional neuroligin 2 maturation and trafficking in Drosophila. J. Mol. Cell Biol. 9, 231-242. https://doi.org/10.1093/jmcb/mjx015

Uezu, A., Kanak, D.J., Bradshaw, T.W.A., Soderblom, E.J., Catavero, C.M., Burette, A.C., Weinberg, R.J., Soderling, S.H., 2016. Identification of an elaborate complex mediating postsynaptic inhibition. Science 353, 1123-1129. https://doi.org/10.1126/science.aag0821

Ulbrich, L., Favaloro, F.L., Trobiani, L., Marchetti, V., Patel, V., Pascucci, T., Comoletti, D., Marciniak, S.J., De Jaco, A., 2016. Autism-associated R451C mutation in neuroligin3 leads to activation of the unfolded protein response in a PC12 Tet-On inducible system. Biochem. J. 473, 423-434. https://doi.org/10.1042/BJ20150274

Varoqueaux, F., 2004. Neuroligin 2 is exclusively localized to inhibitory synapses. Eur. J. Cell Biol. 83, 449-456. https://doi.org/10.1078/0171-9335-00410 
Villa, K.L., Berry, K.P., Subramanian, J., Cha, J.W., Oh, W.C., Kwon, H.-B., Kubota, Y., So, P.T.C., Nedivi, E., 2016. Inhibitory Synapses Are Repeatedly Assembled and Removed at Persistent Sites In Vivo. Neuron 89, 756-769. https://doi.org/10.1016/j.neuron.2016.01.010

White, J.G., Southgate, E., Thomson, J.N., Brenner, S., 1986. The structure of the nervous system of the nematode Caenorhabditis elegans. Philos. Trans. R. Soc. Lond. B. Biol. Sci. 314, 1-340.

Yap, C.C., Winckler, B., 2012. Harnessing the Power of the Endosome to Regulate Neural Development. Neuron 74, 440-451. https://doi.org/10.1016/j.neuron.2012.04.015

Zhang, C., Milunsky, J.M., Newton, S., Ko, J., Zhao, G., Maher, T.A., Tager-Flusberg, H., Bolliger, M.F., Carter, A.S., Boucard, A.A., Powell, C.M., Sudhof, T.C., 2009. A Neuroligin-4 Missense Mutation Associated with Autism Impairs Neuroligin-4 Folding and Endoplasmic Reticulum Export. J. Neurosci. 29, 10843-10854. https://doi.org/10.1523/JNEUROSCI.1248-09.2009

Zhang, Y., Cudmore, R.H., Lin, D.-T., Linden, D.J., Huganir, R.L., 2015. Visualization of NMDA receptor-dependent AMPA receptor synaptic plasticity in vivo. Nat. Neurosci. https://doi.org/10.1038/nn.3936

Zhou, X., Zeng, J., Ouyang, C., Luo, Q., Yu, M., Yang, Z., Wang, H., Shen, K., Shi, A., 2016. A novel bipartite UNC-101/AP-1 $\mu 1$ binding signal mediates KVS-4/Kv2.1 somatodendritic distribution in Caenorhabditis elegans. FEBS Lett. 590, 76-92. https://doi.org/10.1002/1873-3468.12043 